\title{
GESTIÓN DEL TIEMPO Y COMPROMISO ACADÉMICO EN ESTUDIANTES DE PSICOLOGÍA DE LA UNIVERSIDAD PRIVADA NORBERT WIENER, 2019
}

\section{PRESENTADA POR \\ Jonatan Humberto Baños Chaparro}

ASESORA

Luz Marina Sito Justiniano

TESIS

PARA OPTAR EL GRADO ACADÉMICO DE MAESTRO EN EDUCACIÓN CON MENCIÓN EN DOCENCIA E INVESTIGACIÓN UNIVERSITARIA

$$
\text { LIMA - PERÚ }
$$




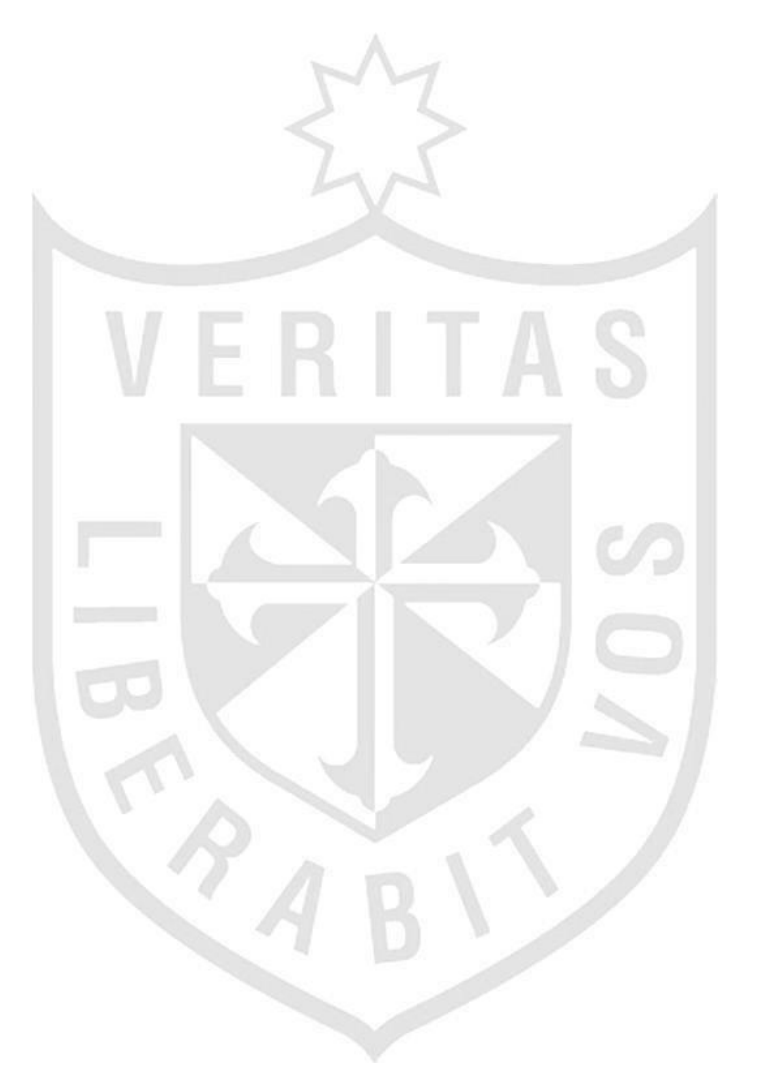

\section{(c) (i) (2) \\ CC BY-NC-ND}

Reconocimiento - No comercial - Sin obra derivada

El autor sólo permite que se pueda descargar esta obra y compartirla con otras personas, siempre que se reconozca su autoría, pero no se puede cambiar de ninguna manera ni se puede utilizar comercialmente.

http://creativecommons.org/licenses/by-nc-nd/4.0/ 

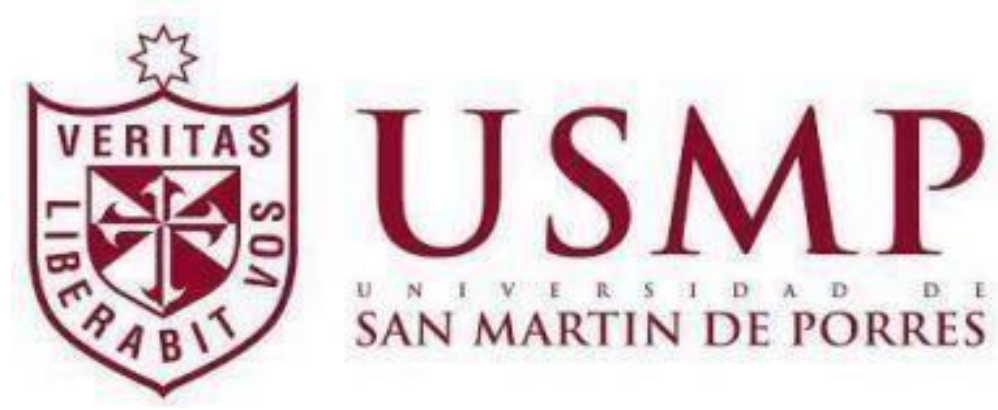

\author{
INSTITUTO PARA LA CALIDAD DE LA EDUCACIÓN \\ SECCIÓN DE POSGRADO
}

\title{
GESTIÓN DEL TIEMPO Y COMPROMISO ACADÉMICO EN ESTUDIANTES DE PSICOLOGÍA DE LA UNIVERSIDAD PRIVADA NORBERT WIENER, 2019
}

\author{
TESIS PARA OPTAR \\ EL GRADO ACADÉMICO DE MAESTRO EN EDUCACIÓN \\ MENCIÓN CON DOCENCIA E INVESTIGACIÓN UNIVERSITARIA
}

PRESENTADO POR:

JONATAN HUMBERTO BAÑOS CHAPARRO

ASESORA:

DRA. LUZ MARINA, SITO JUSTINIANO

LIMA - PERÚ 2020 
GESTIÓN DEL TIEMPO Y COMPROMISO ACADÉMICO EN ESTUDIANTES DE PSICOLOGÍA DE LA UNIVERSIDAD PRIVADA NORBERT WIENER, 2019 
ASESOR Y MIEMBROS DEL JURADO:

ASESOR:

Dra. Luz Marina, Sito Justiniano

PRESIDENTE DEL JURADO:

Dr. Carlos Augusto Echaiz Rodas

MIEMBROS DEL JURADO:

Dr. Jorge Luis Manchego Villarreal

Mg. Augusto José Gonzales Torres 
DEDICATORIA

María Asunción Chaparro Leyva 


\section{AGRADECIMIENTOS}

A mí querida madre, que se encuentra en Estados Unidos. A mis docentes de maestría por sus enseñanzas y apoyo incondicional. A mí asesora, por su amabilidad, apoyo y aprendizaje. Agradezco al director de la escuela profesional de

psicología por permitirme realizar mí investigación en su institución educativa. A los estudiantes de psicología por participar voluntariamente. 


\section{ÍNDICE}

ASESOR Y MIEMBROS DEL JURADO: ......................................................... iii

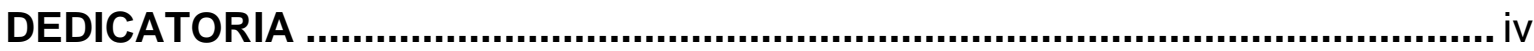

AGRADECIMIENTOS ....................................................................................

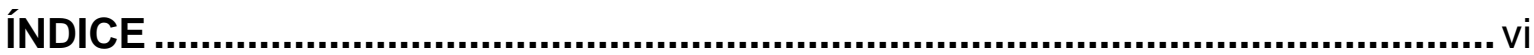

ÍNDICE DE TABLAS .................................................................................... viii

ÍNDICE DE FIGURAS ....................................................................................... ix

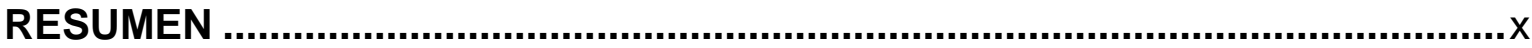

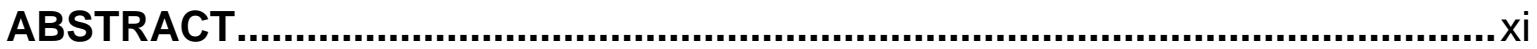

INTRODUCCIÓN ..........................................................................................

CAPÍTULO I: MARCO TEÓRICO ................................................................ 10

1.1 Antecedentes de la investigación ...........................................................

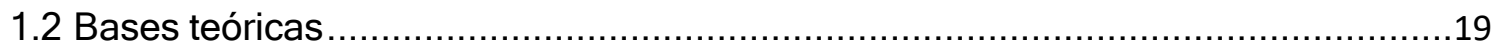

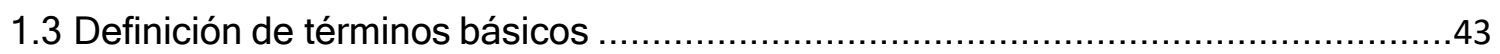


2.1 Formulación de hipótesis principal y derivadas

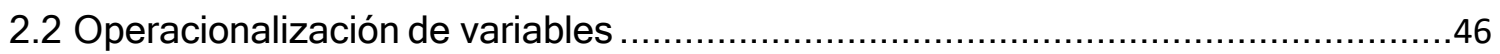

CAPÍTULO III: METODOLOGÍA DE LA INVESTIGACIÓN ..................................49

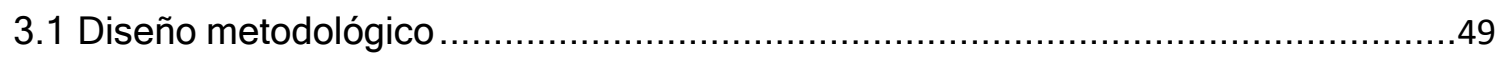

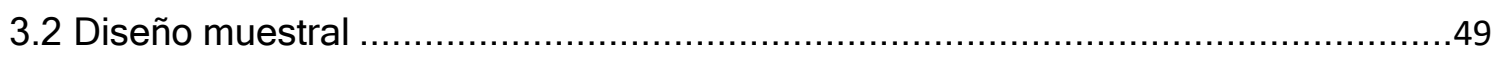

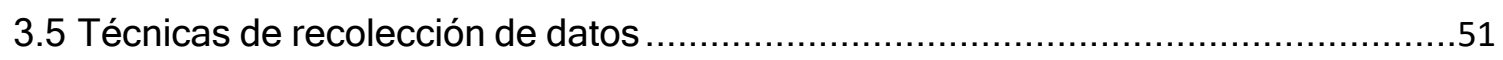

3.6 Técnicas estadísticas para el procesamiento de la información ...........................55

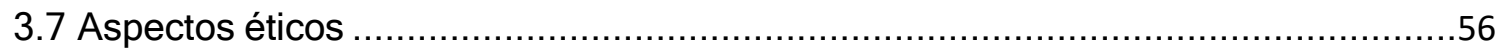

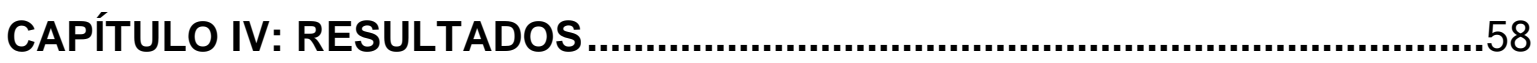

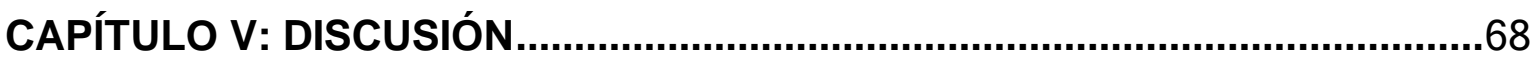

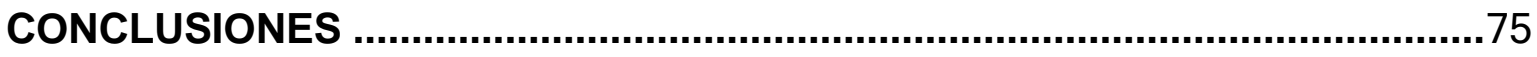

RECOMENDACIONES .....................................................................................

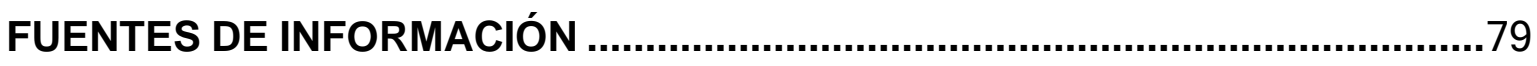

ANEXOS 



\section{ÍNDICE DE TABLAS}

Tabla 1 Población estudiantil de psicología

Tabla 2 Análisis descriptivo de las variables de estudio

Kolmogorov Smirnov de gestión del tiempo y compromiso

Tabla 3 académico

Tabla 4 Relación entre gestión del tiempo y compromiso académico

Relación entre gestión del tiempo y dimensión de compromiso

Tabla 5 académico, expresado en vigor

Relación entre gestión del tiempo y dimensión de compromiso

Tabla 6 académico, expresado en dedicación

Relación entre gestión del tiempo y dimensión de compromiso

Tabla 7 académico, expresado en absorción

Descripción de gestión del tiempo de manera general y según

Tabla 8 dimensiones en los estudiantes de psicología

Descripción de gestión del tiempo de manera general y según

Tabla 9 dimensiones en los estudiantes de psicología 


\section{ÍNDICE DE FIGURAS}

Figura 1 Histograma de gestión del tiempo y compromiso académico.

Diagrama de dispersión entre la gestión del tiempo y el

Figura 2 compromiso académico en estudiantes de psicología de la universidad privada norbert wiener, 2019.

Diagrama de dispersión entre la gestión del tiempo y la

Figura 3 dimensión de compromiso académico expresado en vigor en estudiantes de psicología de la universidad privada norbert wiener, 2019.

Diagrama de dispersión entre la gestión del tiempo y la dimensión de compromiso académico expresado en

Figura 4 dedicación en estudiantes de psicología de la universidad privada norbert wiener, 2019.

Diagrama de dispersión entre la gestión del tiempo y la dimensión de compromiso académico expresado en absorción

Figura 5 en estudiantes de psicología de la universidad privada norbert wiener, 2019.

Porcentaje de la gestión del tiempo de manera general y según

Figura 6 dimensiones en estudiantes de psicología de la universidad privada norbert wiener, 2019.

Porcentaje del compromiso académico de manera general y

Figura 7 según dimensiones en estudiantes de psicología de la universidad privada norbert wiener, 2019. 


\section{RESUMEN}

La investigación tuvo como finalidad conocer la relación entre la gestión del tiempo y el compromiso académico en estudiantes de psicología de la universidad privada norbert wiener. El estudio se ajusta a los lineamientos del método cuantitativo. El tipo de investigación es correlacional y descriptivo, adaptado al planteamiento no experimental y corte transversal. Para la recopilación de la información se utilizó la escala de comportamiento de gestión del tiempo y la escala de compromiso académico. En el estudio participaron voluntariamente 157 mujeres y 52 hombres. Los resultados revelan que la gestión del tiempo y el compromiso académico se correlacionan de manera positiva y estadísticamente significativa $\left(r_{s}=.304, p=\right.$ 001), como también el vigor $\left(r_{s}=.378, p=001\right)$ y absorción $\left(r_{s}=.286, p=001\right)$, aunque el tamaño del efecto es mínimo. Asimismo, se evidenció que no existe correlación con la dedicación $\left(r_{s}=.109, p=117\right)$. Finalmente, los estudiantes de psicología evidencian niveles moderados de gestión del tiempo (52\%) y compromiso académico (55\%).

Palabras clave: Gestión del tiempo, compromiso académico, estudiantes de psicología. 


\section{ABSTRACT}

The purpose of the research was to know the relationship between time management and academic commitment in psychology students from the private university norbert wiener. The study conforms to the guidelines of the quantitative method. The type of research is correlational and descriptive, adapted to the nonexperimental and cross-sectional approach. To collect the information, the time management behavior scale and the academic commitment scale were used. 157 women and 52 men voluntarily participated in the study. The results reveal that time management and academic commitment are positively and statistically significantly correlated $(r s=.304, p=001)$, as well as vigor $(r s=.378, p=001)$ and absorption ( $r s=.286, p=001)$, although the effect size is minimal. Likewise, it was evidenced that there is no correlation with dedication ( $r s=.109, p=117)$. Finally, psychology students show moderate levels of time management (52\%) and academic commitment (55\%).

Keywords: Time management, academic commitment, psychology student 


\section{INTRODUCCIÓN}

El tiempo es un fluir constante, permanente, continuo y absoluto que experimentamos todos los seres humanos paralelamente, aunque esto último puede ser influenciado por otras condiciones; tales como los trastornos mentales, que pueden distorsionar la realidad o las sustancias psicoactivas que alteran el sistema nervioso.

En ese sentido, la gestión del tiempo académico se encuentra dedicado a las demandas estudiantiles, pues es un espacio donde el estudiante establece sus objetivos, crea herramientas para gestionar mejor su tiempo o planifica su organización para un mayor control, lo que le permitirá cumplir sus expectativas académicas.

En esta misma línea, es oportuno mencionar que se ha realizado una encuesta sobre el uso del tiempo a nivel nacional, pues según el Instituto Nacional de Estadística e Informática (INEI, 2010) el 25,1\% del género femenino dedican su tiempo a las actividades educativas, resultado similar sucede en el caso del género masculino con un $24,9 \%$. Asimismo, el estudio revela que el $39,5 \%$ de 
la población superior universitaria participa en su actividad educativa y el 19,7\% para la población superior no universitaria.

Por otra parte, la percepción de la educación superior en nuestro país es alarmante. Recientemente el estudio del Instituto de Investigación de Mercados (IPSOS, 2019) referente a las preocupaciones del mundo. El Perú manifiesta un $35 \%$ de preocupación en relación a la educación, liderando este segmento a comparación de otros paises. Del mismo modo, el INEI (2017) señala que el $30,7 \%$ del grupo etario de 17 a 24 años de edad se matriculó en educación superior (universitaria y no universitaria) siendo un porcentaje muy bajo a nivel nacional.

Aunado a la situación, es importante señalar que la condición socioeconómica es un factor a considerar, pues se revela que el quintil $V(52,9 \%)$ fue mucho mayor que el quintil I $(10,4 \%)$ en relación a las tasas de matrículas en educación superior (INEI, 2017).

Dentro de este marco, el compromiso académico se encuentra vinculado con la dedicación a los estudios, la predisposición de organizar o participar en actividades académicas realizadas por la universidad, escuela profesional o instituciones externas, la vitalidad o satisfacción de las materias que cursa su plan de estudios y, como también, la constante mejora en su formación.

Sin embargo, es preciso indicar que el 1,8\% de la población de 15 a 29 años de edad con educación superior universitaria desertó y el 12,3\% del grupo etario de 25 a 29 años de edad se encuentra con estudios superiores incompletos (INEI, 2017). 
Existen estudios en relación al compromiso académico y la experiencia relativa del tiempo (Daura, 2018). Asimismo, la gestión del tiempo académico en estudiantes que empiezan sus estudios (Durán \& Pujol, 2013), rendimiento académico (Garzón \& Gil, 2017a), procrastinación (Garzón \& Gil, 2017b) y competencia informacional, proponiendo que se incluyan asignaturas sobre cómo manejar el tiempo en las instituciones educativas (Gómez, 2013).

En vista de los datos estadísticos, se puede inferir que los estudiantes universitarios a nivel nacional presentan problemas para gestionar su tiempo académico y el compromiso estudiantil que demandan los estudios, cuyos factores pueden ser económicos o personales.

Es preciso indicar que solo existen estudios a nivel nacional relacionados con el estrés (Monroy, 2017) o con el rendimiento académico (Pilares, 2017), pero no se evidencian investigaciones respecto al manejo del tiempo de los estudiantes peruanos vinculado a su compromiso académico, siendo el presente estudio un primer acercamiento sobre el contexto universitario nacional.

Finalmente, surge el interés porque se aprecia que los estudiantes no gestionan adecuadamente su tiempo académico, no utilizando herramientas para organizar sus actividades académicas, tales como: el uso de listas, libretas de apuntes o incluso marcar fechas limites en un calendario. Asimismo, carecen de objetivos a corto plazo y presentan sus trabajos después de la fecha indicada, lo que conlleva a su vez, a modo de consecuencia, un bajo rendimiento académico y escasa dedicación a los estudios. Por lo tanto, la investigación propone indagar si la gestión del tiempo se encuentra relacionada 
con el compromiso académico en los estudiantes de psicología de una universidad privada de lima.

En ese sentido, se optó por formular la siguiente pregunta general de investigación:

¿Cuál es la relación entre la gestión del tiempo y el compromiso académico en estudiantes de psicología de la universidad privada norbert wiener, 2019?

Por lo tanto, se plantean los siguientes problemas específicos:

PE1: ¿Cuál es la relación entre la gestión del tiempo y el compromiso académico expresado en vigor en estudiantes de psicología de la universidad privada norbert wiener, 2019?

PE2: ¿Cuál es la relación entre la gestión del tiempo y el compromiso académico expresado en dedicación en estudiantes de psicología de la universidad privada norbert wiener, 2019

PE3: ¿Cuál es la relación entre la gestión del tiempo y el compromiso académico expresado en absorción en estudiantes de psicología de la universidad privada norbert wiener, 2019?

PE4: ¿Cuál es la relación de la gestión del tiempo de manera general y según dimensiones que muestran los estudiantes de psicología de la universidad privada norbert wiener, 2019?

PE5: ¿Cuál es la relación del compromiso académico de manera general y según dimensiones que muestran los estudiantes de psicología de la universidad privada norbert wiener, 2019? 
En esta misma línea, de acuerdo a los problemas planteados de la investigación, se redactan congruentemente el objetivo general y los objetivos específicos. Por lo tanto, el objetivo general que argumentó la investigación fue el siguiente:

Determinar la relación entre la gestión del tiempo y el compromiso académico en estudiantes de psicología de la universidad privada norbert wiener, 2019.

Asimismo, los objetivos específicos fueron los siguientes:

OE1: Determinar la relación entre la gestión del tiempo y el compromiso académico expresado en vigor en estudiantes de psicología de la universidad privada norbert wiener, 2019.

OE2: Determinar la relación entre la gestión del tiempo y el compromiso académico expresado en dedicación en estudiantes de psicología de la universidad privada norbert wiener, 2019.

OE3: Determinar la relación entre la gestión del tiempo y el compromiso académico expresado en absorción en estudiantes de psicología de la universidad privada norbert wiener, 2019.

OE4: Describir la gestión del tiempo de manera general y según dimensiones que muestran los estudiantes de psicología de la universidad privada norbert wiener, 2019.

OE5: Describir el compromiso académico de manera general y según dimensiones que muestran los estudiantes de psicología de la universidad privada norbert wiener, 2019. 
En la actualidad, la mayoría de las instituciones educativas de condición básica y superior, no evidencian la implementación en los planes curriculares de cursos vinculados con la adecuada administración del tiempo académico, siendo una habilidad indispensable para el cumplimiento de los objetivos académicos propuestos.

Se han realizado estudios en el extranjero que indican que la gestión del tiempo es un repertorio de conductas que se dirigen a utilizar efectivamente el tiempo, a través de una retahíla de actividades planificadas para el cumplimiento de metas establecidas. Asimismo, la dedicación y logro de las metas estudiantiles genera en el estudiante universitario componentes motivacionales y de autocontrol referente al aprendizaje. No obstante, existen estudios que señalan que aquello no necesariamente implica mayor satisfacción o autonomía. Inclusive, podría estar influenciado por factores sociales o métodos de estrategias, encontrando resultados contradictorios.

En el Perú, existen datos estadísticos referente a la administración del tiempo en estudiantes universitarios peruanos. Los resultados revelan la poca dedicación e inadecuado uso del tiempo académico, expresándose en la prórroga de tareas estudiantiles, carencia de orden, planificación y priorización de actividades dedicadas al estudio, no establecimiento de metas educativas o estrategias de afrontamiento, factores que podrían influir un menor compromiso académico. Asimismo, a nivel nacional se evidencian estudios de la gestión del tiempo de estudiantes universitarios asociada a la procrastinación, rendimiento y estrés académico. Sin embargo, no se han reportado estudios que indiquen la asociación del comportamiento del tiempo y el compromiso académico en 
nuestro país. Siendo de mucha importancia determinar su relación, suponiendo que una adecuada gestión acaecería un mayor compromiso.

En ese sentido, la investigación procuró brindar información para su consideración, puesto que los resultados poseerán valores teóricos para futuras investigaciones y como también valores prácticos para una mayor aproximación del constructo a través de talleres o su implementación en los planes curriculares para el desarrollo de conductas regulativas del tiempo dedicado a los estudios y reforzamiento del compromiso académico. Lo que permitirá a su vez, un valor de carácter social, divulgando la importancia de la problemática actual y sus posibles consecuencias que derivan el uso inapropiado del tiempo académico.

Los alcances de la investigación serán de utilidad para las instituciones educativas superiores y referenciales para la educación básica. Asimismo, para los docentes, psicólogos e investigadores afines.

Asimismo, de acuerdo al presupuesto planteado, fue viable la realización de la investigación desde un aspecto técnico y económico, puesto que los recursos de bienes y servicios fueron accesibles. Asimismo, respecto a los instrumentos de recolección de datos, evidencian adecuadas propiedades psicométricas de validez y fiabilidad. Permitiendo una apropiada evaluación de los participantes y eludiendo sesgos estadísticos que perjudiquen las conclusiones de la presente investigación.

Por otra parte, el estudio presenta una viabilidad ética, puesto que se recurrió a la autorización del director de la escuela académico profesional de psicología para el ingreso en las aulas académicas y la ejecución de los instrumentos 
psicométricos para la recopilación de la información. Asimismo, se dispuso del tiempo necesario para la aplicación de los instrumentos, corrección y digitación de la misma.

Por otro lado, la investigación presentó las siguientes limitaciones, tales como: la carencia de antecedentes nacionales e internacionales sobre investigaciones asociadas a la medición de la gestión del tiempo académico y compromiso académico, por lo que se optó indagar las variables independientemente y asociadas a otros constructos afines. Otra limitación que se presentó en el estudio fue en relación a los docentes o tutores encargados del aula académica, puesto que dos docentes no brindaron permiso para ingresar al aula y aplicar los instrumentos psicométricos de recopilación de información pese a que se le presentó el permiso otorgado por el director de la escuela académica profesional de psicología.

Por otra parte, el presente documento de investigación se adhiere a la siguiente estructura:

Capítulo I: Sección dedicada a las investigaciones y teorías precedentes del estudio, como también la explicación terminológica. Por lo tanto, se mencionan los antecedentes nacionales e internacionales, las teorías, modelos o enfoques relacionados a los constructos del estudio y la descripción de las dimensiones.

Capítulo II: Asociado a los planteamientos de hipótesis general y específicos que se argumentó la investigación. Asimismo, la definición del proceso de medición de las variables, es decir, la operacionalización. 
Capítulo III: Vinculada a los procedimientos y técnicas empleadas en la investigación. Se explica la metodología aplicada en el desarrollo del estudio, señalando los métodos y procedimientos estadísticos.

Capítulo IV: Dedicado a la presentación de los hallazgos estadísticos, expresados coherentemente con los objetivos de la investigación y redacción de la interpretación.

Capítulo V: Destinado al disentimiento de los resultados reportados de los participantes. La afirmación o rechazo de las hipótesis propuestas y la relación de los precedentes estudios nacionales e internacionales.

Por último, se mencionan las conclusiones y recomendaciones, es decir, las aportaciones del presente estudio. 


\section{CAPÍTULO I: MARCO TEÓRICO}

\subsection{Antecedentes de la investigación}

\section{Antecedentes internacionales}

Adams y Blair (2019) investigaron el impacto del comportamiento de gestión de tiempo sobre el rendimiento de los estudiantes de ingeniería, buscarón examinar los comportamientos de gestión del tiempo autorreportados por los estudiantes de ingeniería de una universidad publica de Trinidad y Tobago, siendo un estudio descriptivo y correlacional. Evaluarón a 75 estudiantes quienes respondierón la Escala de Comportamiento del Tiempo (ECT). Los hallazgos de la investigación evidencian que la sensación de controlar el tiempo se correlaciona significativamente con el promedio general de calificaciones y que existen otros factores que influyen tales como: técnicas de estudio, resolución de problemas, la socioeconomía y la personalidad. Asimismo, no existen diferencias según el género de los participantes ni tampoco considerando su edad. 
García (2019) en su trabajo de investigación titulado La autorregulación de la gestión del tiempo para el aprendizaje en línea en la formación profesional española: efectos de la cuantificación personal del tiempo de estudio, para optar el grado académico de doctorado, cuyo objetivo principal fue evaluar los modelos organizativos a nivel institucional, junto con las herramientas tecnológicas y los recursos didácticos que caracterizan el e-learning de las enseñanzas de formación profesional en todo el territorio español. El estudio es de tipo descriptivo y correlacional, de enfoque cuantitativo, diseño pre experimental y muestreo censal. La investigación de se dividió en tres fases: la primera fase comprende el análisis del e-learning en la formación profesional en la cual participaron 17 expertos en el área; la segunda fase corresponde al análisis psicométrico del Cuestionario de autorregulación del aprendizaje en entornos en linía (QAAEL) con la participación de 170 estudiantes universitarios y, por último, la tecera fase donde se implementó el programa experimental con la participación de 553 estudiantes universitarios. Los hallazgos sugieren que los diferentes escenarios en el ambiente en línea $(F(4,510)=33.63, p<.001, \eta 2$ $=.20$ ) afectan significativamente las variables dependientes del estudio. Además, existen diferencias significativas en el tiempo de dedicación al estudio, dependiendo del escenario empleado en el ambiente en línea $(F(2,556)=72.15$, $p<.001, \eta 2=.36$ ). En ese sentido, si el estudiante no logra planificar su tiempo de estudio, es probable que no sea capaz de organizar el desarrollo de las tareas de aprendizaje.

Gutiérrez, Tomás y Alberola (2018) investigaron el Apoyo docente, compromiso académico y satisfacción del estudiante de una universidad pública de República Dominicana., cuyo objetivo principal fue analizar si el compromiso académico 
influye sobre la satisfación en el alumnado mediante el apoyo autonomo del profesor. La investigación corresponde a un estudio correlacional, de enfoque cuantitativo y planteamiento no experimental, corte transversal y muestreo por conveniencia. Se evaluó a 870 estudiantes que respondieron el Cuestionario Climático de Aprendizaje, Inventario de Compromiso Académico y la Escala de Conectividad. Los autores señalan que el apoyo que brinda el profesor se correlaciona altamente con las dimensiones del compromiso académico, tales como energía $(r=.53)$, dedicación $(r=.48)$ y absorción $(r=.52)$, asimismo con la satisfacción. Del mismo modo, sostienen que el desarrollo de la autonomía en los estudiantes de pregrado favorece mayor compromiso, mayor vinculación con la institución educativa y el aprendizaje.

Grez (2018) en su investigación denominada Efecto de una experiencia de aprendizaje por proyecto sobre el aprendizaje autodirigido, gestión del tiempo y rendimiento académico en estudiantes de tecnología médica de una universidad tradicional, para optar el grado académico de doctorado, el objetivo principal fue analizar el efecto de una experiencia de aprendizaje por proyecto sobre el aprendizaje autodirigido y el nivel de gestión del tiempo, en relación con el rendimiento académico en estudiantes de Tecnología Médica mención Morfofisiopatología y Citodiagnóstico de una universidad tradicional. El estudio es de tipo descriptivo y relacional, de enfoque cuantitativo, diseño pre experimental y muestreo no probabilístico por convenencia. En ese sentido, participaron 14 estudiantes de ambos sexos que respondieron el cuestionario de gestión del tiempo (CGT), la escala de aprendizaje autodirigido en alumnos de ciencias de la salud (EAA-C) y se obtuvo acceso a las notas obtenidas en los diferentes momentos del programa. Los resultados indicaron que ligeramente se 
incrementó los niveles de autoconfianza $t(13)=-4.19 ; p<0.001$ y pensamiento analítico $t(13)=-2.56 ; \mathrm{p}<0.05$ del aprendizaje autiridigido. Del mismo modo, se evidenció un aumento en la planificación del tiempo $t(13)=-1.92 ; p<0.05$. Además, se reportan correlaciones significativas de la planificación del tiempo con la organización del aprendizaje $(r=.84 ; \mathrm{p}<0.01)$; deseo de aprender $(r=.55$; $p<0.04)$ y pensamiento analítico $(r=.72 ; p<0.01)$, sugiriendo que el programa para el aprendizaje basado en proyecto desarrolla competencias de aprendizaje autónomo y hace al aprendiz más reflexivo y planificado.

Mohamadkhani, Naderi, Zagheri, Ahmadi y Hosseini (2017) en su trabajo llamado asociación entre las habilidades de comportamiento del tiempo, la ansiedad y la motivación académica de los estudiantes de enfermería de Teherán, cuyo propósito fue indagar si existe relación entre ambos constructos en los estudiantes de enfermería en tres Universidades Médicas, Teherán, Irán. El estudio se ajusta al planteamiento no experimental, corte transversal y muestreo estratificado. Evaluaron a 441 estudiantes que contestarón el Cuestionario de Gestión del Tiempo, Inventario de Ansiedad Estado Rasgo y la Escala de Motivación Educativa. Se evidenció niveles moderados de las habilidades de gestión de tiempo (49\%), ansiedad estado (58\%) rasgo (60\%) y motivación académica (58\%). Asimismo, se evidencia relación significativa entre motivación y comportamiento del tiempo. Por otro lado, se describe una relación abversa entre la capacidad de administrar el tiempo y la ansiedad estado-rasgo.

Oriol, Mendoza, Covarrubias y Molina (2017) estudiaron las emociones positivas, apoyo a la autonomía y rendimiento estudiantil universitario como principio intermediario del compromiso académico y la autoeficacia, comprobando si la autonomía y el estado de animo positivo percibido dentro del aula son 
constructos que pronostican el rendimiento estudiantil mediante la autoeficacia y el compromiso académico. La investigación corresponde a un estudio correlacional, de enfoque cuantitativo y planteamiento no experimental, corte transversal y muestreo por conveniencia. Asimismo, los 428 alumnos que colaboraron en el estudio respondieron al cuestionario de Compromiso Académico, Escala de Competencia Percibida, Cuestionario de Clima de Aprendizaje, Escala de emocionalidad y por último, una Escala ad hoc respecto al rendimiento académico. Los resultados señalan que la autoeficacia, comprendida como la amplitud del alumno para realizar excelentes trabajos vinculados a los estudios, pronostica mayor el nivel de compromiso académico y a su vez, el compromiso mejora el rendimiento estudiantil.

Gaeta y Cavazos (2016) en su investigación llamada asociación entre comportamiento de tiempo de académico, autorregulación del aprendizaje y desempeño académico en alumnos de educación superior, buscarón responder si un rendimiento académico alto, medio o bajo se vincula con el comportamiento dedicado a los estudios, los procesos de autorregulación del aprendizaje y el desempeño académico como consecuencia. Evaluarón a 735 estudiantes mediante las calificaciones promedio al inicio del curso, un cuestionario de preguntas abiertas elaborado por los propios autores y un instrumento de 10 cuestiones. Los resultados demuestran que los estudiantes con promedio más alto dedican más tiempo a los estudios, vinculando mayor seguridad y confianza para administrar su aprendizaje a comparación de los estudiantes con promedio de bajo nivel. En ese sentido, se evidenció que el dedicar más tiempo a los estudios mejora significativamente el rendimiento académico y la autorregulación del aprendizaje. 


\section{Antecedentes nacionales}

Alcántara (2019) en su investigación denominado Alumnos de alto rendimiento: compromiso académico, estrés académico y bienestar en alumnos de una universidad privada de Lima, para optar el título profesional de licenciado en psicología, cuyo objetivo fue determinar si existe relación entre el compromiso académico, estrés y bienestar en estudiantes universitarios de alto rendimiento. La investigación es un estudio correlacional con enfoque cuantitativo, se ajusta a un planteamiento no experimental, corte transversal y muestreo de bola de nieve. Los participantes fueron 50 estudiantes quienes respondieron la Escala de compromiso académico, Cuestionario de estrés académico y Escala SPANE y Florecimiento. Los resultados demuestran que el compromiso académico y el florecimiento, entendido como el bienestar subjetivo, se relacionan positivamente $(r=.59, p<.01)$, aunque el compromiso y el estrés se relacionan de manera inversa $(r=.51, p<.01)$. Asimismo, mediante un análisis de regresión, la autora señala que cuando se incrementa el nivel de bienestar, disminuye la intensidad de estrés. El cual predice un incremento del compromiso vinculado con los estudios por parte de los estudiantes.

Urco (2019) investigó la Asociación entre el comportamiento del tiempo y procrastinación académica en alumnos de ingeniería de una universidad privada de Junín, para optar el grado académico de magister, cuyo objetivo principal fue averiguar la relación entre el comportamiento del tiempo, entendido como un componente principal para el alcance de los aprendizajes educativos y la procrastinación académica. La investigación fue descriptiva y correlacional, ajustándose a un planteamiento no experimental y enfoque cuantitativo, con muestreo aleatorio simple. Los participantes fueron 214 estudiantes quienes 
respondieron el Cuestionario de Comportamiento del Tiempo y la Escala de Procrastinación académica. Los hallazgos señalan que existe una asociación inversa entre el comportamiento del tiempo y la procrastinación $(r=-.084)$ aunque no es significativa $(p=.401)$. Asimismo, se evidencian correlaciones positivas entre el comportamiento del tiempo y la autorregulación de actividades $(r=.113)$ vinculadas a la conducta operante de organización y alcance de logros académicos, por otro lado, de manera inversa con la postergación de actividades $(r=-.041)$ asociada a la prórroga de las demandas académicas.

Quiroz (2019) en su investigación titulada Gestión del tiempo, rigor científico y estrés académico en estudiantes de modalidad semipresencial, décimo semestre de una universidad privada de Lima, para optar el grado académico de doctorado, tuvo como objetivo general identificar la relación entre la gestión del tiempo, el rigor científico y el estrés académico en estudiantes universitarios bajo la modalidad semipresencial, que cursan el noveno y décimo semestre de una universidad privada. El estudio es de tipo descriptiva y correlacional, de enfoque cuantitativo y diseño no experimental con corte transversal. La muestra fue probabilística aleatorio simple y estuvo conformada por 221 estudiantes universitarios, que respondieron los cuestionarios de gestión del tiempo, riegor científico y estrés académico elaborados por el propio autor. Los hallazgos señalan que la gestión del tiempo se relaciona con el rigor científico $\left(r_{s}=.738^{* *}\right)$ y con el estrés académico $\left(r_{s}=.567^{*}\right)$. Además, el rigor científico tambíen se relaciono con el estrés académico $\left(r_{s}=.522^{*}\right)$. Se evidencia que los participantes presentan adecuados niveles de gestión del tiempo $(71,5 \%)$ y rigor científico (67,7\%). Sin embargo, se reportan niveles altos de estrés académico $(83,7 \%)$, considerando que en el plan curricular de estudios semipresenciales se deben 
priorizar actividades o charlas que disminuyan el nivel de estrés de los estudiantes.

Fernández (2018) en su investigación Estrés y compromiso académico en estudiantes de una universidad privada de Lima, para optar el título profesional de licenciado en psicología, tuvo como objetivo determinar la asociación entre el estrés académico y compromiso académico en un grupo de estudiantes universitarios de la carrera profesional de psicología entre el tercer y duodécimo ciclo. El estudio fue no probabilístico de tipo intencional en donde evaluó a 200 estudiantes con el Inventario SISCO del estrés académico y la Escala Utrecht Work Engagement Student. Encontró que a mayores indíces de estímulos estresores menores serán los niveles de compromiso de los estudiantes universitarios. Asimismo, se menciona que a mayor frecuencia de actividades en el aula, menores serán los niveles de los factores vigor y dedicación.

Pilares (2017) en su trabajo Administración del tiempo y rendimiento académico en alumnos de la Universidad Andina del Cusco, 2016, para optar el título profesional de economista, cuyo objetivo fue averiguar la asociación entre la administración del tiempo y el rendimiento académico en los alumnos de la Escuela Profesional de Economía. El estudio es de tipo descriptivo y correlacional, de planteamiento no experimental. Evaluó a 80 alumnos quienes respondierón una encuesta elaborada para fines de la investigación. Los resultados demuestran que los estudiantes planifican sus actividades y elaborán un proyecto de vida académico, presentando mayor predisposición de rendimiento. 
Monroy (2017) en su trabajo llamado Estrés académico y manejo de tiempo en almunos universitarios de Lima, Perú; para optar el título profesional de psicológa clínica, cuyo objetivo principal fue asociar y describir ambos constructos en un grupo de alumnos universitarios que se encuentran matriculados en los primeros ciclos de la Facultad de Ciencias e Ingeniería de una universidad privada de Lima. El estudio es de tipo descriptivo y correlacional, de planteamiento no experimental, en donde evaluó a 186 alumnos que respondierón al Inventario SISCO del estrés académico y la Escala de Manejo de Tiempo. Encontró que ambas variables se correlacionan de manera negativa. Sin embago, el género femenino refleja mayor uso de herramientas para la administrar su tiempo a comparación con el género masculino. Asimismo, los alumnos repitentes presentan mayores reacciones físicas y comportanmentales.

Flores (2017) en su investigación denominada Relación de la gestión del tiempo y estrés laboral en el personal de la sede administrativa de la Gerencia Regional de Salud Moquegua, para optar el grado académico de magister, cuyo objetivo fue establecer la relación entre la gestión del tiempo y el estrés laboral de los trabajadores del área administrativa de la gerencia regional de salud de Moquegua. El estudio es de tipo descriptivo y correlacional, de diseño no experimental y corte transversal, donde se aplicó a 112 trabajadores el cuestionario de gestión del tiempo del directivo (GTD) y la escala de estrés laboral de la OIT-OMS. Los hallazgos señalan que el $40.2 \%$ del personal del área administrativa evidencia un nivel inadecuado de gestión del tiempo y respecto al estrés laboral, se reporta que el $71.4 \%$ presenta un nivel bajo. Además, los resultados sugieren que la relación entre la gestión del tiempo y el estrés laboral es significativa pero inversa $\left(X^{2}=14.319, p=0.003\right)$, siendo necesario que la 
empresa realice capacitaciones sobre cómo gestionar adecuadamente el tiempo con la finalidad de disminuir el estrés y optimizar el proceso laboral en el área.

\subsection{Bases teóricas}

\subsubsection{GESTIÓN DEL TIEMPO}

\section{Definición}

De acuerdo con García, Pérez, Talaya y Martínez (2008) indican que la gestión del tiempo académico es un procedimiento, es decir, el estudiante durante la gestión utiliza métodos y percibe su control, estableciendo objetivos de acuerdo al tiempo dedicado a los estudios.

Por otro lado, Wang, Kao, Huan y Wu (2010) conceptualizan la gestión del tiempo como una capacidad primaria y necesaria para el ser humano, indicando que más allá de su importancia dentro de los campos académicos o laborales, es a su vez; imprescindible para mejorar la salud.

En esta misma línea, Krause y Coates (2008) señalan que la capacidad de gestionar promueve el éxito académico y que la constancia genera una habituación o el aprendizaje de un nuevo comportamiento en el organismo del individuo, lo cual contribuye al estudiante mayores estrategias de aprendizaje vinculados a sus estudios.

Asimismo, Claessens, Van eerde, Rutte y Roe (2004) determinan que son conductas de planificación, lo cual implica interés, voluntad y esfuerzo por parte del estudiante respecto al aprendizaje, a través de la motivación respecto a diversas asignaturas y el alcance de los objetivos propuestos a corto y mediano plazo. 


\section{Modelos teóricos de la gestión del tiempo}

Modelo teórico de Britton y Tesser

En primera instancia, los autores señalan que previamente a la construcción del modelo teórico, se basaron en un modelo descrito anteriormente (Britton \& Glynn, 1989) que se encuentra relacionado con potenciar el rendimiento intelectual, derivada de los estudios de sistemas operativos de computadoras y específicado en varios componentes.

Britton y Glynn (1989) señalan que el sistema operativo de una computadora regula los procesos de información que son limitados. Los autores consideran que los métodos de información de los estudiantes universitarios, también son limitados y que se pueden administrar, realizando esfuerzos mayores para una adecuada gestión. Asocian el sistema operativo y los métodos de información de los estudiantes, como procesos similares de distribución y regulación del tiempo.

Por lo tanto, Britton y Tesser (1991) plantearon tres factores relevantes en su teoría, tales como; la medida de planificación a corto periodo; entendido como la disposición del estudiante a organizar sus demandas académicas durante el día o en el transcurso de la semana, mediante una relación de propósitos y prioridades. El siguiente factor se detalla como las actitudes de tiempo; es decir, la actitud de los estudiantes respecto a su uso de tiempo en relación a los estudios y su modo edificante de emplearlo. Por último, el factor denominado como la planificación a largo período; componente vinculado con la instauración de metas durante el ciclo de estudios, asumiendo un cronograma de fechas o 
anticipándose al cumplimiento de tareas. No obstante, el modelo fue ampliado y reorganizado posteriormente, estableciendo cuatro factores (Macan, 1994).

Asimismo, los autores explican una comparación entre un sistema operativo de una computadora y la manera de gestionar el tiempo, sucede que el sistema administra los recursos de su información para un mayor rendimiento operativo y, los estudiantes a través de la gestión del tiempo, pueden realizar la misma administración en aspectos académicos de diferentes grados de dificultad (Britton \& Tesser, 1991).

En consecuencia, los autores descubrieron que la organización del tiempo en los planes de estudios fueron indicadores relevantes para el rendimiento académico; sucede que una adecuada administración del tiempo contribuye a un mayor aprendizaje y calidad de resultados, lo cual conlleva al cumplimiento o el alcance de los objetivos académicos. Asimismo, indican que de alguna manera los estudiantes logran desarrollar conductas vinculadas a la planificación a corto o largo período, asumiendo una actitud provechosa hacia el tiempo.

Finalmente, a modo de reflexión, respecto a la población de estudio, no existen datos referenciales de la institución sobre como los estudiantes gestionan su tiempo ni mucho menos existen asignaturas en los programas generales o especializados vinculadas al desarrollo de la gestión del tiempo. No obstante, la investigación pretende brindar dicha información para su consideración, aunque como señala Gómez (2013) es importante su implementación en los diseños curriculares basados en competencias. 
Modelo de Macan

Macan, Shahani, Dipboye y Phillips (1990) señalan que el comportamiento inadecuado de gestionar el tiempo, como por ejemplo: no establecer adecuadamente el tiempo para las actividades académicas o laborales, congestión de tareas en el último momento de su entrega o la escasa planificación de prioridades o metas. Probablemente pueden ser fuentes principales de fatiga, agotamiento, tensión y disminución del rendimiento académico.

En este sentido, existen investigaciones empíricas que con esfuerzo han intentado explicar la naturaleza correlacional con otros constructos, tales como estrés (Monroy, 2017), procrastinación (Garzón \& Gil, 2017b), y ansiedad (Mohamadkhani, Naderi, Zagheri, Ahmadi, \& Hosseini, 2017). Sin embargo, por las propias caracteristicas de los estudios, impiden manifestar declaraciones causales.

No obstante, los resultados parecen indicar que el entrenamiento puede cambiar la forma en que uno pasa el tiempo, es decir, la dedicación a ciertas actividades. Aunque no necesariamente un adecuado entrenamiento signifique la disminución de problemas psicológicos y físicos, tales como el estrés, la ansiedad, cefalea o incluso mejore el rendimiento en los campos laborales o académicos. En esta misma línea, Macan et al. (1990) señalan que diversos autores concuerdan respecto a las recomendaciones de la gestión del tiempo. Manifiestan identificar las necesidades para categorizarlas de acuerdo a su importancia y posteriormente la asignación de fechas y horarios para su ejecución con fines de culminación. 
Aunque las mujeres presenten adecuados comportamientos respecto a la gestión del tiempo (Macan et al., 1990). No necesariamente sientan que controlan su tiempo, experimentado sobrecarga de roles, baja satisfacción o tensiones somáticas. Las deficiencias mencionadas anteriormente indican dos aspectos muy importantes. El primer aspecto se dirige a los malos comportamientos de gestionar su tiempo. El segundo aspecto parece indicar que los estudiantes no tienen clarificado sus deberes y responsabilidades, ocasionando insastifacción general.

Estudios previos a la medición de la gestión del tiempo (Macan et al., 1990) manifiestan la multidimensionalidad del constructo, expresado en cuatro factores relevantes, los cuales se relacionan con la conceptualización de Lakein (1973). Posteriormente, dentro del modelo planteado por Macan (1994) se enfatiza en la consideración de la percepción del control sobre el tiempo, siendo el primer estudio vinculado a la conducta de gestionar el tiempo; examinando nociones más específicas como la teoría del comportamiento planificado (Ajzen, 1991).

Por lo tanto, Macan (1994) propone que los comportamientos de gestionar el tiempo no se encuentran directamente relacionados con problemas psicologicos o somáticos, sino sobre la percepción del tiempo, es decir; no es debido a las conductas de administrar el tiempo sino el dominio percibido sobre estas mismas. Por lo tanto, Macan et al. (1990) desarrollaron una investigación donde indican que los estudiantes que presentan mayor dominio del tiempo, menores eran las tensiones escolares y somáticas a comparación de los que no presentaban dominio de su tiempo. 
En consecuencia, Macan (1994) establece cuatro dimensiones que representa el constructo de gestión del tiempo, tales como: el establecimiento de objetivos y prioridades; entendido como la inclinación y preferencia para la realización de las demandas académicas, adquiriendo el estudiante un mayor logro de sus objetivos. Asimismo, establece otra dimensión denominada herramientas para la gestión del tiempo; la cual se encuentra asociada a las estrategias de manejo del tiempo, es decir, el empleo de métodos de cuadros de horarios, el registro de las tareas pendientes como el descarte de ellas mismas, uso de libretas y otros.

En esta misma línea, la tercera dimensión que plantea Macan (1994) lo define como las preferencias por la desorganización; vinculadas hacia el desorden en relación con el abordaje de las tareas académicas y la conservación de una planificación de estudios. Por último, detalla otra dimensión como la percepción de control sobre el tiempo; asumiendo la apreciación del estudiante referente al dominio de su tiempo, es decir, adquiere un sentido de como asignar su tiempo a las actividades.

En este sentido, el modelo planteado por Macan (1994) confirmo los supuestos de percepción del tiempo, pues el estudio reportó que los trabajadores que percibían su control sobre el tiempo presentaban mayores satisfacciónes laborales en comparación de los trabajadores que no percibían o carecían sobre dicho control.

Modelo de gestión personal del tiempo

Gestionar adecuadamente el tiempo nos permite aumentar la eficiencia del uso del tiempo para el desempeño de la tarea. La gestión presupone un control 
consciente sobre la cantidad de tiempo que se dedica a tipos particulares de actividades, incrementando la eficiencia y calidad de un producto de la actividad. En ese sentido, Vladimirovich, Kabdullinovna, Vasilievich y Anatolyevich (2015) plantearon un modelo de gestión personal del tiempo basado en los siguientes principios:

El primer principio se denomina establecimiento de metas, cuyo objetivo es la formulación de propósitos por parte del individuo. El propósito es un primer paso en la gestión, debe ser formulado por el propio estudiante de acuerdo a sus intereses y generalmente se establece un resultado ideal anticipado que se debe alcanzar. Si no se define el propósito del día, semana o mes, se observará un pasatiempo exclusivamente sin objetivo y sin proposito. Por ello, establecer los propósitos brindan la oportunidad de ejercer un control deliberado sobre la administración de nuestro tiempo y, por lo tanto, promover el logro del éxito académico o laboral. Los autores señalan que los requisitos principales al determinar los propósitos son: su orientación en el tiempo, consistencia, concreción, mensurabilidad, accesibilidad y, al mismo tiempo, la mayor complejidad posible, puesto que se desea alcanzar un resultado ideal (Vladimirovich, Kabdullinovna, Vasilievich \& Anatolyevich, 2015).

El segundo principio se denomina prioridad. Se comprende como el rango de los propósitos y tareas de importancia. Por lo tanto, los autores enfatizan que la gestión eficaz del tiempo se basa en la lista de las principales prioridades establecidas anteriormente en el primer principio de establecimiento de metas. El estudiante debe considerar su tiempo disponible y distribuirlo según la importancia que ha asignado a cada actividad, con el fin de alcanzar el 
resultado deseado (Vladimirovich, Kabdullinovna, Vasilievich \& Anatolyevich, 2015).

El tercer principio es la puntualidad. La importancia de asignar el término concreto de desempeño a cada actividad. La actividad que no se localiza con precisión a tiempo generalmente no se logra culminar en absoluto e interfieren en el establecimiento del primer principio. Los términos designados deben ser viables y prácticos para la implementación o realización efectiva de la actividad. Considerar una fecha de culminación de la actividad es la obligación del propio estudiante y otorga una responsabilidad que debe asumir (Vladimirovich, Kabdullinovna, Vasilievich \& Anatolyevich, 2015). Asimismo, es importante considerar que si no se logra el cumplimiento de estas actividades en un tiempo establecido, puede conllevar a que el estudiantes experimente estados emocionales inestables (Adams \& Blair, 2019). Por ello, es necesario que las actividades sean prácticas y coherentes con la realidad del estudiante.

El cuarto principio es la verificación. Es decir, el estudiante revisa sus actividades y verifica su realización de acuerdo a su prioridad y establecimiento de metas. El éxito de la realización de este principio en muchos aspectos se define por la claridad de los indicadores elegidos de eficiencia y los criterios de su evaluación. Por último, el quinto principio es el equilibrio, donde el estudiante reflexiona sobre las fortalezas y debilidades de las decisiones tomadas, y también las consecuencias a largo plazo que implica aquello. Por lo tanto, los autores mencionan que el estudiante debe mantener un equilibrio óptimo, ya sea físico o psicológico para evitar cualquier problema relacionado con la salud (Vladimirovich, Kabdullinovna, Vasilievich \& Anatolyevich, 2015). 
En ese sentido, los autores señalan que la la vida académica, laboral o inclusive ambas, puede generar una presión emocional debido a la planificación constante de actividades, responsabilidades y compromisos. Por ello, el modelo no solo enfatiza en la importancia de gestionar adecuadamente el tiempo, sino que precisa en cómo un estudiante puede beneficiarse del tiempo, mantiendo su integrida física y psicológica.

\section{Leyes sobre el tiempo}

La gestión del tiempo es comprendida en la actualidad como una competencia o un factor relevante para alcanzar objetivos personales o académicos. De hecho, algunas características principales que permiten diferenciarlo de otros recursos, es la capacidad de independencia (equidad) que establece en el mundo real, puesto que todos disponemos del mismo intervalo de tiempo (Bustínduy, 2015). Otra característica atribuible al tiempo, es que no requiere de un costo (gratuidad), aunque el tiempo no es acumulable (inelasticidad) ni recuperable (Bustínduy, 2015).

En ese sentido, los griegos ya comprendían estas características y distinguían el tiempo de dos diferentes formas. En particular, denominaban Crono a un tiempo lineal o flujo, es decir, un tiempo abstracto general o determinado. De hecho, también era concebido como un dios que conducía el movimiento de los cielos y la permanencia del tiempo. Por otro lado, también era denominado como Kairós que representaba un tiempo oportuno y gestionado. Aunque en principio resultaba confuso, los griegos indicaron que la principal diferencia entre ambas formas de definición del tiempo, es que la primera es de naturaleza cuantitativa, mientras que la segunda es cualitativa. Para los griegos, el tiempo 
era el mejor guía en cualquier actividad del ser humano y, por esta razón, se puede apreciar que era considerado un dios (Bustínduy, 2015).

La relevancia del tiempo en la vida del ser humano y los antecedentes de la antigua grecia, permitieron que posteriormente se establecieran leyes sobre el tiempo. Por ejemplo, la ley de fraisse que contempla el tiempo como una dimensión objetiva o subjetiva, cuyo fin se orienta a las actividades ejercidas. La ley de rendimientos crecientes explica que mientras transcurre el tiempo, la capacidad de concentración, disposición, entre otros, diminuyen su intensidad (Bustínduy, 2015).

En esta misma línea, la ley de carlson indica que abandonar una actividad posteriormente requerirá mucho esfuerzo para retomarla. Aquello concuerda con la ley de parkinson que menciona los limites del tiempo que se debe proponer a cada actividad. El principio de pareto señala que solo un mínimo porcentaje del tiempo empleado para una actividad es destinado para el objetivo, mientras que la ley de murphy y la ley del coste de oportunidad, indican que toda actividad requiere más tiempo y que el ser humano debe aprender a valorar el tiempo que dispone (Bustínduy, 2015).

\section{Factores que influyen la gestión del tiempo}

Indudablemente administrar adecuadamente el tiempo permite un mayor orden de nuestras actividades estudiantiles, del trabajo, del ambito familiar o responsabilidades personales, como por ejemplo ir a pagar los servicios básicos o comprar los alimentos para la semana (Baños-Chaparro, 2020b). Incluso en la actualidad existen herramientas digitales que permiten organizar el tiempo que una persona dispone durante la mañana, tarde y noche. 
Facilitando la gestión del tiempo a través del ordenamiento y ejecución de las actividades a través de notificaciones, alarmas, calendarios, agendas, notas, entre otros. Sin embargo, el uso de aquellas herramientas no necesariamente soluciona el problema de gestionar el tiempo de una persona.

Es necesario que las herramientas sean utilizadas como métodos de apoyo y no como solución de problemas. Por lo tanto, la utilización de las herramientas entrena (indirectamente) al usuario la capacidad de poder planificar. La planificación, como señala Bird (2004), debe realizarse con criterio. Los criterios consisten en clasificar cada actividad por su afinidad e importancia. Es importante asignarle un tiempo establecido para su realización y revisión. Asimismo, los criterios no se encuentran asociados estrictamente a aspectos laborales o académicos, sino que también se consideran aspectos dedicados para la persona misma, es decir, implementar tiempo para descansar, reflexionar o entretenimiento.

Es oportuno aprender a planificar y mayor aún hacerlo con criterio. Sin embargo, la planificación basada en criterios podría ser afectada por variables imprevistas. De acuerdo con Laboris (2008), existen los denominados ladrones del tiempo, término definido por el autor. Los ladrones del tiempo es un conjunto de sucesos imprevistos, como por ejemplo las visitas inesperadas de personas desconocidas o conocidas, la solución del problema dependerá del asunto por el cual acude la persona y el grado de confianza que se dispone, aunque en personas conocidas será más factible a comparación de los desconocidos. Otro elemento importante son las reuniones no programas en el trabajo o ámbito vecinal, que involucra la participación de grupos masivos de personas, la escasa puntualidad y la extensión del horario establecido de la reunión. 
Asimismo, la comunicación inadecuada sin claridad y explicación, puede ocasionar confusiones y posteriormente problemas laborales o académicos, derivando un mayor esfuerzo de tiempo para su solución. Del mismo modo el desorden, los encuentros casuales, las conversaciones desligadas a las actividades laborales o académicas y la insuficiente disciplina personal, son ladrones de tiempo que sustituyen las horas dedicadas a una actividad planificada con criterio, provocando la prolongación de las actividades y una sobrecarga de tareas.

Marín, Aranda y Guzmán (2007) señalan que para desarrollar adecuadas conductas de administrar el tiempo, se debe tener en cuenta los siguientes componentes, tales como: el componente cultural vinculado a las formas y costumbres de trabajo, el componente estructural de la empresa asociada al establecimiento del horario del personal, el componente de comunicación entre los participantes expresado en contradicciones, confusiones y desinformación, el componente de la tarea vinculada a las funciones del cargo laboral y el componente de recursos humanos entendido como las conductas inadaptas del gerente, jefes o coordinadores.

Asimismo, Marín et al. (2007) manifiestan que existen otros componentes a considerar, como por ejemplo la personalidad, los rasgos del ser humano pueden influir en las estrategias planteadas para el entrenamiento del comportamiento de gestión del tiempo. El entorno social es otro componente a considerar, puesto que los patrones sociales modelan el repertorio conductual de las personas. Del mismo modo los componentes individuales expresados en los debilitamientos o deficit conductuales del individuo, disminuyendo las conductas adaptativas aprendidas. Finalmente, considerar los problemas 
físicos o psicológicos derivados de la sobrecarga o mala organización del tiempo, los cuales influirian en el estado de animo, bajo rendimiento o poca dedicación a las actividades planificadas. Inclusive, las redes sociales son otro tipo de ladron de tiempo y probablemente su uso excesivo esté relacionado con sintomatología depresiva (Baños-Chaparro, 2020a).

\section{Uso efectivo del tiempo}

Dilucidar sobre el uso efectivo del tiempo es involucrar también el avance de las nuevas tecnologías debido a su gran contribución en el siglo ventiuno. Es importante incorporarlo debido a que en la actualidad la educación a sufrido muchos cambios. Las TIC permiten una nueva modalidad de educación a distancia, facilitando a estudiantes con problema de ubicación o tiempo, la posibilidad de acceder a una educación superior (Romero \& Barberà, 2013).

La evaluación continua a través de las TIC en estudiantes con formación a distancia, permite una mayor administración del tiempo de los participantes (Romero \& Barberà, 2013) concediendo al estudiante corregir y estudiar cuando deseen, y no necesariamente cuando pueden.

Por lo tanto, el tiempo es considerado un componente indispensable para el enseñanza y aprendizaje de los conocimientos (Huamán, 2019), siendo un recurso valioso. En este sentido, para usar efectivamente el tiempo debe realizarse diversas funciones. Incorporar un plan de acompañamiento en la regulación del tiempo de los docentes, puesto que se pueden encontrar fuera del salón o como también no ejercer un enseñanza interactiva entre alumno y maestro (León, 2019). Los monitoreos semanales probablemente mejoren la 
gestión óptima del tiempo, con el propósito de acrecentar el aprendizaje y modelar una cultura institucional sobre el uso adecuado del tiempo.

Asimismo, el uso efectivo del tiempo puede verse impedido por los siguientes problemas, tales como: el consenso de inactividad voluntaria por parte de los profesores, los desastres naturales que afectan las jordanas de estudio o la carente dedicación voluntaria del estudiante hacia las clases (León, 2019), desbordan las estrategias planteadas para el comportamiento adaptativo del tiempo. Un tiempo que es remunerado por parte del gobierno nacional y que no es regulado adecuadamente.

Finalmente, es necesario señalar que el uso efectivo del tiempo, es decir, la optimización del tiempo disponible y su mayor aprovechamiento mediante la planificación con criterio, promueve en el estudiante independencia y autonomía (Marcén \& Martínez, 2012). El grado de autonomía no siempre se encontrará adherido a la institución educativa, sino fuera de la institución, puesto que disponen de mayor tiempo libre.

\subsubsection{COMPROMISO ACADÉMICO}

\section{Definición}

De acuerdo con Schaufeli, Martínez, Marques, Salanova y Bakker (2002a) el compromiso académico es una condición saludable que involucra emociones

positivas y provechosas para la regulación de nuestro aprendizaje y salud. Sucede que no es una circunstancia temporal, sino que el comportamiento se mantiene en el tiempo.

Según Salanova, Martínez y Llorens (2004) definen el compromiso académico como un fenómeno acicate, es decir, estimula al estudiante a realizar acciones 
o actuar de determinada manera para lograr alcanzar sus objetivos académicos de corto y mediano plazo. Además, existe una planificación basada en los intereses del propio estudiante y con el propósito de lograr los resultados deseados.

Por otro lado, Medrano, Moretti y Ortiz (2015) señalan el compromiso académico como el reflejo de una adecuada integración al entorno estudiantil y que se exterioriza en conductas firmes hacia el rendimiento de los estudios.

Asimismo, es definido también como la comodidad que presentan los estudiantes ante la contienda académica, logrando así, un ahínco comprometedor entre sujeto y proceso de aprendizaje, cuyo fin es la satisfacción académica y emocional (Parra \& Pérez, 2010).

\section{Teorías y modelos del compromiso académico}

Teoría del rol

En principio, fue Kahn en 1990 quien describe por primera vez el engagement, señalandolo como la energía del trabajador que se encuentra dirigida para alcanzar los objetivos de una organización. Siendo el ahínco y la motivación , los componentes principales que refuerzan al individuo.

En esta misma línea, Kahn realizó una investigación donde encontró que un porcentaje menor de los empleados de una organización mostraban energía, motivación y entusiasmo por sus áreas o centro de trabajo general, resultados inusuales que en principio podrían entenderse como la satisfacción o motivación laboral, pero sucede que no era así. 
En este sentido, el autor realizó una teoría que comprendía lo señalado anteriormente, la cual detalla que la percepción del individuo de su contexto de trabajo y de sus propias características personales fomenta las condiciones psicológicas que influyen en su decisión de engage más completamente en su rol de trabajo (Kahn, 1990).

Asimismo, Kahn (1990) establecio tres planteamientos psicológicos que se vinculan con las funciones laborales de las personas comprometidas, las cuales son las siguientes:

- Significancia psicológica: relacionada con la percepción del individuo en su propio rendimiento expresado como la fuerza física, cognitiva o emocional, pues experimentan la significancia como las acciones propias que aportan hacia su centro laboral, definido como un vinculo persona-organización, puesto que un desempeño de un rol laboral conlleva la asunción de una identidad Kahn (1990). Asimismo, la congruencia de valores personaorganización se refiere a la similitud entre los valores de los trabajadores y el sistema cultural de valores de la organización (Cable \& Edwards, 2004).

- Seguridad psicológica: vinculada con la sensación de autonomía y autoeficacia de la propia capacidad para alcanzar los objetivos planteados y organizados por el propio individuo. Asimismo, las vinculaciones con los demás compañeros del campo laboral y el soporte percibido de la organización vinculado a la contribución que realiza, instaura en el individuo habilidades de liderazgo que contribuyen a su confianza y compromiso laboral. En este sentido, el liderazgo transformador eleva los intereses de sus compañeros, generando reflexión y aprobación sobre los propósito planteados (Bass, 1990). 
- Disponibilidad psicológica: vinculada con la impresión de disponer los recursos necesarios para su rol laboral. En ese sentido, una de las influencias clave sobre la disponibilidad psicológica es el nivel general de confianza que una persona tiene en sus propias capacidades y en su estatus, así como la conciencia de sus comportamientos, actitudes y relaciones con su entorno (Kahn, 1990).

Por lo tanto, la teoría de kahn define el engagement como las propias características personales y su vinculación con el desempeño laboral, en donde la significancia, seguridad y disponibilidad son factores a considerar. Asimismo, en relación a la población de estudio, los estudiantes universitarios evidencian habilidades académicas entendidas como las características personales y su identidad, seguridad y confianza con sus estudios, vinculadas con las condiciones psicológicas que refuerzan al estudiante.

Teoría de las demandas y recursos laborales

Fue elaborada por Demerouti, Bakker, Nachreiner y Schaufeli (2001) aunque el modelo ah sido ampliado (Bakker \& Demerouti, 2013) pues la Teoría de las demandas y los recursos laborales (DRL) es la más representativa en el área de investigaciones del entorno laboral, puesto que ofrece mayor comprensión del bienestar y rendimiento laboral del personal de una empresa.

La teoría de DRL se inspiró básicamente en la teoría del proyecto laboral y la tensión laboral que relativamente ignoraban la presencia de factores estresores y, como también componentes motivacionales respecto a los recursos. En este sentido, la teoría de DRL conjuga las demandas y recursos, como resultados directos e inversos sobre la tensión laboral y la energía. Asimismo, es incluso 
utilizado como predictor del burnout (Bakker, Demerouti \& Euwema, 2005) la conectividad con jornada laboral (Lewing, Xanthopoulou, Bakker, Dollard \& Metzer, 2007) o como el compromiso (Hakanen, Bakker \& Schaufeli, 2006).

Los autores indican que la popularidad de la teoría probablemente radique en sus fundamentos, tales como:

- Flexibilidad: los entornos laborales mayormente se dividen en demandas y recursos laborales, los que permite a la teoría de DRL ser aplicable en diferentes campos profesionales, individualmente de sus características propias.

En esta misma línea, se describe a las jornadas laborales vinculadas a los aspectos físicos, psicológicos, organizacionales o sociales de las actividades laborales que involucran un ahínco permanente. Por otra parte, los recursos laborales comparten los mismos aspectos, sin embargo, todo aquello se encuentra dirigido a reducir las exigencias de la jornada laboral; como también el alcance de objetivos y aprendizajes (Bakker \& Demerouti, 2013).

- Dos procesos: los autores señalan que las actividades y los recursos laborales son componentes que orientan dos procedimientos individuales, tales como:

- Deficiencia de la salud: es debido a las demandas laborales que mayormente se vinculan con el agotamiento o padecimientos somáticos. Las exigencias del campo laboral conllevan problemas de salud como la fatiga, problemas gastrointestinales, lumbalgia o incluso el absentismo, lo que conduce a un bajo rendimiento laboral (Bakker \& Demerouti, 2013).

- Proceso motivacional: caso contrario sucede en este apartado, los recursos laborales son motivaciones extrínsecas ya que permiten el 
afrontamiento de las demandas e intrínsecas porque brindan oportunidades de aprendizaje y desarrollo personal, implicando al sujeto a un mayor compromiso institucional (Gálvez, Moreno \& Mingote, 2009).

- Interacciones entre demandas y recursos laborales: es preciso indicar que ambos procesos son diferentes pero que, a su vez poseen el mismo efecto. La interacción de ambas, permite predecir el bienestar del trabajador, sucede que los recursos pueden influir en el rendimiento; ya sea mitigando las exigencias o generando mayor motivación y compromiso por las demandas elevadas (Bakker \& Demerouti, 2013).

- Recursos personales: son las autoevaluaciones afirmativas internas y externas vinculadas a la capacidad de poder controlar e influir en el entorno de una manera asertiva, incluso en situaciones desfavorables, empleando sus recursos y capacidad de solución de problemas (Hobfoll, Johnson, Ennis \& Jackson, 2003).

Finalmente, a modo de conclusión, la teoría de DRL nos permite detallar y pronosticar, signos y síntomas físicos o psicológicos en relación a las exigencias del trabajo y, como también la satisfacción de los trabajadores. Asimismo, es importante relacionar la teoría de $\mathrm{DRL}$ con la presente población de estudio, ya que las demandas laborales en el campo de la educación son entendidas como los trabajos en equipo, las diversas asignaturas, la participación de cursos electivos, trabajos individuales y exposiciones, los cuales deben asumir los estudiantes con responsabilidad y compromiso, estableciendo objetivos, planificando y organizando un horario, siendo autoeficaces e optimistas, entendido como sus recursos personales.

Modelo teórico de Salanova, Bresó y Schaufeli 
Dentro de los estudios de Salanova, Bresó y Schaufeli (2005) definen el compromiso como un elemento de la motivación intrínseca que experimentan los estudiantes en relación a los estudios, siendo esta motivación persistente en el tiempo. Asimismo, los autores señalan que para su mayor comprensión, existen tres dimensiones: vigor, dedicación y absorción.

En este sentido, el vigor se encuentra vinculado con un mayor nivel de energía de los estudiantes mientras estudian, siendo de carácter persistente, incluso cuando se presentan dificultades. Por otro lado, la dedicación se asocia con el significado atribuido a los estudios, es decir, el entusiamo, la importancia y el orgullo de los estudiantes relacionados a su carrera profesional (Salanova, Bresó \& Schaufeli, 2005).

Finalmente, la absorción, definida como la atención plena del estudiante, se aprecia como un estado de felicidad y una mayor noción de que el tiempo transcurre mucho más rápido, debido a la connotación de placer, motivación y disfrute de sus actividades académicas (Salanova, Bresó \& Schaufeli, 2005).

Modelo de compromiso general

Aunque en principio los estudios de compromiso fueron vinculados al área laboral (Schaufeli, Salanova, Gonzalez \& Bakker, 2002b), posteriomente este constructo fue ampliado e investigado en el área académica (Schaufeli \& Bakker, 2003). Sin embargo, en los últimos años ha sido vinculado a cualquier otra actividad del ser humano. Sucede que no hay razón psicológica convincente por la cual el compromiso se deba restringir solo al área laboral o académica (Schaufeli, 2017). En ese sentido, otras actividades también pueden realizarce con energía y determinación, como los diversas actividades 
deportivas, eventos o programas de voluntariados, diferentes pasatiempos en entornos físicos o digitales, incluso las responsabilidades domésticas.

El modelo de compromiso general que propone el mismo autor original de los modelos anteriores, sugiere que el compromiso se encuentra en cualquier actividad que involucre la atención y participación de un individuo. En la teoría de rol (Kahn, 1990), se explicaba que el compromiso expresado de manera física, cognitiva y emocional, se asociaba a los roles de un trabajador de una empresa, siendo estos roles diversos (persona encargada de la seguridad del establecimiento, persona encargada de recibir la mercadería, etcétera). Por ello, el autor indica que también los deportistas, amas de casa, trabajadores independientes, personas que participan en voluntariado, etcétera; pueden estar comprometidos ya que ocupan roles sociales (Schaufeli, 2017).

El autor argumenta que cualquier actividad, y no solo aquellas actividades que pueden involucrarse en el campo laboral, puede llevarse a cabo con energía, participación y concentración. Siguiendo este razonamiento, una persona puede experimentar una sensación de compromiso cuando busca un pasatiempo, arregla cosas en casa o lee. En otras palabras, no parece haber una razón psicológica convincente por la cual el compromiso como un estado psicológico positivo y satisfactorio deba restringirse al trabajo y no pueda generalizarse a otras actividades diarias (Schaufeli, 2017).

Por lo tanto, Schaufeli (2017) define al compromiso general como "un estado mental positivo y satisfactorio que se asocia con la realización de actividades diarias de cualquier tipo y se caracteriza por el vigor, la dedicación y la absorción" (p. 10). En ese sentido, el concepto que brinda el autor permite 
comprender que el compromiso se encuentra presente en todo tipo de actividades y que pueden coincidir o no, con las actividades laborales, siendo estas mismas, otro indicador más del compromiso.

A partir de aquello, crea un instrumento de evaluación denominado Utrecht General Engagement Scale (UGES) para confirmar si el modelo teórico propuesto puede ser evaluado y medido con el apoyo de la psicometría, cuyo fin es traducir la evidencia en la práctica. Los hallazgos indicaron un buen ajuste para el modelo unidimensional y consistencia interna. Asimismo, el autor señala que, al igual que el compromiso laboral, el compromiso general se caracteriza por el vigor, la dedicación y la absorción, pero a diferencia del compromiso laboral, está relacionado con el desempeño de las actividades diarias de cualquier tipo (Schaufeli, 2017).

\section{Enfoques teóricos del compromiso académico}

El estudio del compromiso académico en Latinoamérica ha sido reciente (Arguedas, 2010) a comparación de America del norte (Kuh, 2003). Las investigaciones señalan que el compromiso académico se puede explicar a través de dos factores, tales como: el estudiante principiante y el contexto general, no necesariamente institucional (Daura, 2015). Aunque existen circunstancias que predominan en el constructo, como por ejemplo la motivación del alumno (Schuetz, 2008), el diálogo entre el estudiante y el maestro (Umbach \& Wawrzynski, 2005), la interacción entre los mismos alumnos (Porter, 2006), o como también la familia, las amistades, el trabajo y la salud (Law, 2005). 
Asimismo, existen enfoques para dilucidar el constructo. Zepke y Leach (2010) determinan cuatro enfoques. El primero se encuentra vinculado a la motivación del alumno, expresado en el comportamiento activo de participación, involucración y regulación del aprendizaje. El segundo enfoque se denomina compromiso transaccional, entendido como la observación de la comunicación del alumno y profesor o del alumno entre alumno. El tercer enfoque esta asociado a la institución, es decir, el apoyo que brinda al estudiante en su desarrollo de aprendizaje, a través de docentes calificados, recursos disponibles y ambiente adecuado. El cuarto enfoque se encuentra vinculado a la participación de los ciudadanos, puesto que la educación que brinda una institución educativa promueve cambios en los patrones sociales.

No obstante, Zepke, Leach y Butler (2010) añaden tres nuevos enfoques respecto al compromiso académico. El primero es la relación entre el estudiante y el maestro, vuelven a reafirmar la relación óptima como método que favorece o refuerza el compromiso estudiantil. El segundo es la comunicación entre los mismos alumnos, expresado en los trabajos grupales, siendo otro método más para adherir mayor compromiso. Por último, el tercer componente son los familiares, los amigos y las emociones del estudiante, puesto que los autores consideran que aquellas variables no institucionales pueden influir en la regulación del aprendizaje y el compromiso.

Es oportuno mencionar que existen otras propuestas teóricas referente al constructo. Por ejemplo, la teoría constructivista explica que el alumno desarrolla su concepto aprendizaje a través de la asimilación e incorporación del conocimiento, puede ser por recepción o por descubrimiento guiado o autónomo, lo que implica involucrarse con el aprendizaje (Krause \& Coates, 
2008). Por otra parte, la teoría sociocognitiva concede un aspecto principal las actividades del alumno en relación a los estudios, a su ambiente familiar y personal. El comportamiento adaptativo del alumno favorece la asimilación del aprendizaje (Gavala \& Flett, 2005). Asimismo, la teoría sociocrítica interpreta el compromiso académico como una ideología política y social, creando las condiciones necesarias para las relaciones organizadas (McMahon \& Portelli, 2004).

Fredericks, Blumenfeld y Paris (2004) definen que el compromiso académico esta estructurado en tres aspectos importantes. El primero es el compromiso comportamental, reflejado en la emisión conductual del estudiante en relación a las normas de convivencia del aula académica. El alumno manifiesta comportamientos adecuados en clases, como estar atento a las explicaciones del docente, la participación ordenada y voluntaria, la flexibilidad y respeto de las opiniones de otros alumnos, y la asimilación para la ejecución de las tareas (Daura, 2015). El segundo es el compromiso emocional, vinculado a la manifestación del área afectiva del alumno, es decir, el alumno demuestra interés en sus estudios, se encuentra satisfecho o feliz por el cumplimiento de sus tareas o como también emociones negativas, como sentirse triste por no entregar la tarea en la fecha indicada, sentirse ansioso o inclusive aburrido (Fredericks et al. 2004). Por último, el compromiso cognitivo se expresa mediante el interés del estudiante por seguir aprendiendo, la aceptación de nuevos retos académicos y el establecimientos de metas a corto y largo plazo (Trowler, 2010).

Por otro lado, Coates (2007), indica que existen estilos de compromiso académico, los cuales son los siguientes: el estilo colaborativo refiere la 
expresión emocional positiva hacia la institución educativa, manifestando comportamientos de participación en los talleres, charlas o conferencias realizadas por la institución o la sugerencia de nuevas actividades, asimismo la comunicación con los docentes, alumnos y personal administrativo. El estilo intenso se caracteriza por la dedicación a los estudios, el bienestar de asistir a los ambientes de la institución educativa y la apreciación positiva de los docentes. El estilo pasivo se encuentra vinculado a la carencia de participación e interés de los alumnos. Mientras que el estilo independiente evidencia a los estudiantes autodidactas, los cuales perciben que los docentes se encuentran comprometidos con la institución y la enseñanza.

En este sentido, el compromiso académico será mayor o menor, de acuerdo a los componentes personales o contextuales (Daura, 2015). Puede ser influenciado por factores motivacionales o individuales del propio individuo. Como también por la propia institución, mediante la evaluación y apoyo continuo del personal académico, ambientes disponibles y enseñanza reflexiva.

\subsection{Definición de términos básicos}

Establecimiento de objetivos y prioridades: Vinculada a la capacidad del alumno a preferir y elegir las actividades académicas de su programa de estudio para alcanzar sus metas educativas de corto y mediano plazo (García \& Pérez, 2012).

Herramientas para la gestión del tiempo: Orientado al uso de métodos de manejo del tiempo, como el uso de la libreta o breviario, la confección del índice de actividades académicas o la comprobación de las tareas ya finalizadas (García \& Pérez, 2012). 
Percepción del control del tiempo: Es la apreciación del estudiante sobre como administra su tiempo. Lo cual genera emociones positivas (alegría, satisfacción) al cumplir las actividades académicas, extracurriculares o responsabilidades vinculadas al estudio (García \& Pérez, 2012).

Preferencias por la desorganización: Asociada a la organización o planificación del estudiante respecto a sus actividades académicas y la conducta constante de mantener en orden sus estudios (García \& Pérez, 2012).

Vigor: Es la fuerza, dedicación y acción del estudiante respecto a los trabajos de su programa de estudios. Asimismo, es la proclamación de conductas de superación, valor y constancia pese a los problemas o inconvenientes ajenos a la vida académica (Carrasco, De la corte \& León, 2010).

Dedicación: Vinculada con el compromiso estudiantil, es decir; la manifestación de altos niveles de rendimiento que conllevan emociones positivas, los cuales contribuyen a sus actividades académicas y condiciones de salud personal. En este sentido, el individuo asume una actitud responsable hacia los estudios.

Absorción: Es la entrega y disposición de un individuo vinculado a sus actividades académicas, es decir; el sujeto percibe sensaciones de placer al realizar sus funciones asignadas e incluso el tiempo carece de importancia. 


\section{CAPÍTULO II: HIPÓTESIS Y VARIABLES}

\subsection{Formulación de hipótesis principal y derivadas}

\subsubsection{Hipótesis principal}

La gestión del tiempo y el compromiso académico están relacionados de manera directa y estadísticamente significativa en estudiantes de psicología de la universidad privada norbert wiener, 2019.

\subsubsection{Hipótesis derivadas}

HE1: Cuanto mayor es la evidencia de gestión del tiempo mayor también es él compromiso académico vinculado con el vigor en estudiantes de psicología de la universidad privada norbert wiener, 2019.

HE2: Cuanto mayor es la evidencia de gestión del tiempo mayor también es él compromiso académico vinculado con la dedicación en estudiantes de psicología de la universidad privada norbert wiener, 2019.

HE3: Cuanto mayor es la evidencia de gestión del tiempo mayor también es él compromiso académico vinculado con la absorción en estudiantes de psicología de la universidad privada norbert wiener, 2019. 


\subsection{Operacionalización de variables}

\subsubsection{Definición conceptual}

La gestión del tiempo académico es definida como un conglomerado de capacidades o patrones dirigidos hacia un orden o estructura de planificación, cuyo objetivo es disminuir las demandas académicas (Lay \& Schouwenburg, 1993).

El compromiso académico es un estado motivacional que se encuentra relacionado con los estudios. Asimismo, más que un estado transitorio, el compromiso se encuentra vinculado con el estado emocional y cognitivo, lo cual es constante en el tiempo porque no se limita a situaciones particulares (Schaufeli, Salanova, Gonzalez \& Bakker, 2002b).

\subsubsection{Definición operacional}

La gestión del tiempo académico estriba en la disposición del estudiante para el ordenamiento de las planificaciones estudiantiles y el alcance de los objetivos a corto plazo. En este sentido, se encuentra vinculado con la instauración de objetivos y metas, instrumentos para administrar el tiempo, noción de controlar el tiempo y la desorganización.

El compromiso académico refiere a la actitud del alumno vinculado a la dedicación de los estudios, es decir; la percepción, concentración y satisfacción con las labores de la formación académica. Asimismo, es la comunicación entre el maestro y el alumno, cuyo objetivo es el alcance de los conocimientos prácticos y empíricos de la carrera de estudio. 


\begin{tabular}{|c|c|c|c|c|}
\hline Variable & Dimensiones & Indicadores & Ítems & Instrumento \\
\hline \multirow{4}{*}{$\begin{array}{l}\text { Gestión del } \\
\text { tiempo }\end{array}$} & $\begin{array}{c}\text { Establecimiento de } \\
\text { objetivos y } \\
\text { prioridades }\end{array}$ & $\begin{array}{l}\text { - Disposición del estudiante para } \\
\text { elaborar las actividades } \\
\text { académicas. } \\
\text { - Facilidad para estructurar sus } \\
\text { metas a corto y largo plazo. }\end{array}$ & $1,5,7,9,13,17,21,24,27,31$ & \multirow{4}{*}{$\begin{array}{c}\text { Time Management } \\
\text { Behavior } \\
\text { Questionnaire } \\
\text { (TMBQ) } \\
\text { Nunca = } 1 \\
\text { Pocas veces = } 2 \\
\text { Algunas veces = } 3 \\
\text { Habitualmente }=4 \\
\text { Siempre }=5\end{array}$} \\
\hline & $\begin{array}{l}\text { Herramientas para } \\
\text { la gestión del tiempo }\end{array}$ & $\begin{array}{l}\text { - Emplea estrategias vinculadas } \\
\text { a su tiempo académico. } \\
\text { - Planifica la distribución de su } \\
\text { tiempo a través de } \\
\text { herramientas tangibles. }\end{array}$ & $\begin{array}{c}3,6,11,14,18,22,25,28,32 \\
33,34\end{array}$ & \\
\hline & $\begin{array}{l}\text { Percepción del } \\
\text { control del tiempo }\end{array}$ & $\begin{array}{l}\text { - Reflexiona sobre la utilidad de } \\
\text { su tiempo y horario. } \\
\text { - Identifica las responsabilidades } \\
\text { académicas. }\end{array}$ & $4,10,15,19,29$ & \\
\hline & $\begin{array}{l}\text { Preferencias por la } \\
\text { desorganización }\end{array}$ & $\begin{array}{l}\text { - Percibe y ejecuta mejor sus } \\
\text { actividades, cuando no lo } \\
\text { planifica. } \\
\text { - La organización y planificación } \\
\text { son métodos irrelevantes. }\end{array}$ & $2,8,12,16,20,23,26,30$ & \\
\hline
\end{tabular}




\begin{tabular}{|c|c|c|c|c|}
\hline \multirow{3}{*}{$\begin{array}{l}\text { Compromiso } \\
\text { académico }\end{array}$} & Vigor & $\begin{array}{l}\text { - Percepción de sentirse con } \\
\text { energía durante las actividades } \\
\text { académicas. } \\
\text { - Resistencia física y mental } \\
\text { durante los estudios }\end{array}$ & $1,4,8,12,15,17$ & $\begin{array}{c}\text { Utrecht Work } \\
\text { Engagement } \\
\text { Student - Scale } \\
\text { (UWES-17) }\end{array}$ \\
\hline & Dedicación & $\begin{array}{l}\text { - Compromiso con las } \\
\text { actividades académicas. } \\
\text { - Motivación e interés hacia los } \\
\text { estudios. }\end{array}$ & $2,5,7,10,13$ & \multirow{2}{*}{$\begin{array}{c}\text { Nunca }=0 \\
\text { Casi nunca }=1 \\
\text { Algunas veces }=2 \\
\text { Regularmente }=3 \\
\text { Bastantes veces }= \\
4 \\
\text { Casi siempre }=5 \\
\text { Siempre }=6\end{array}$} \\
\hline & Absorción & $\begin{array}{l}\text { - Concentración durante las } \\
\text { clases y el desarrollo de sus } \\
\text { tareas académicas. } \\
\text { - Disfrute y satisfacción con las } \\
\text { actividades académicas. }\end{array}$ & $3,6,9,11,14,16$ & \\
\hline
\end{tabular}

Fuente: Elaboración propia (2019) 


\section{CAPÍTULO III: METODOLOGÍA DE LA INVESTIGACIÓN}

\subsection{Diseño metodológico}

El estudio se adecua a los parámetros del enfoque cuantitativo debido a que se formuló hipótesis de investigación expresadas en la relación de las variables para contrastarlo con la evidencia empírica. Asimismo, es un estudio de tipo básico y de nivel descriptivo y correlacional, debido a que se realizó análisis de frecuencia y porcentajes para conocer el comportamiento de los constructos del presente estudio de manera individual y, como también, estimar la correlación entre ambos constructos, indagando si la relación inferencial es significativa y si se encuentra en dirección positiva o negativa (Ato \& Vallejo, 2015).

En esta misma línea, el diseño de investigación es no experimental porque no hubo manipulación de ninguna variable por parte del investigador durante todo el proceso. Asimismo, es de corte transversal puesto que los instrumentos fueron aplicados una vez en cada participante (Ato \& Vallejo, 2015).

\subsection{Diseño muestral}

\subsubsection{Población}


La población estuvo conformada por los alumnos de la escuela académica profesional de psicología de pregrado de la universidad privada norbert wiener ubicada en el distrito de Cercado de Lima. Asimismo, los estudiantes estaban matriculados en el periodo 2019-II, en los diferentes turnos (mañana y noche) programados por la escuela académica profesional de psicología. Asimismo, los participantes fueron de ambos sexos y se encontraban cursando desde primer ciclo hasta decimo ciclo.

De acuerdo a la población de estudio, se detalla en la siguiente tabla los ciclos académicos programados en el periodo 2019-II y la cantidad de estudiantes matriculados. Asimismo, es necesario indicar que la siguiente descripción cuantitativa es referente a los turnos de mañana y noche.

\section{Tabla 1}

Población estudiantil de psicología

\begin{tabular}{|c|c|}
\hline Ciclo & Población \\
\hline 1 & 76 \\
\hline 2 & 63 \\
\hline 3 & 70 \\
\hline 4 & 59 \\
\hline 5 & 61 \\
\hline 6 & 33 \\
\hline 7 & 26 \\
\hline 8 & 29 \\
\hline 9 & 18 \\
\hline 10 & 22 \\
\hline Total & 450 \\
\hline
\end{tabular}

Fuente: Elaboración propia (2019) 


\subsubsection{Muestra}

En ese sentido, para averiguar el tamaño mínimo indispensable cuya muestra sea representativa, se requirió del siguiente enunciado matemático delimitado para población finita (Bernal, 2006). Por lo tanto, asumiendo la ejecución del enunciado, se obtiene un tamaño representativo de 209 estudiantes.

$$
N=\frac{Z^{2} P \cdot Q \cdot N}{E^{2}(N-1)+Z^{2} \cdot P .}
$$

Q

Donde $Z$ elevado al cuadrado es el parámetro estadístico de confianza de noventa y cinco por ciento, la $\mathrm{P}$ y $\mathrm{Q}$ representa la probabilidad de éxito, la $\mathrm{E}$ considera la transigencia de error $\mathrm{y}$, por último, $\mathrm{N}$ que refiere la magnitud de población. En ese sentido, la técnica de muestreo de selección de los participantes fue probabilística, utilizando el método aleatorio simple de acuerdo a un marco muestral.

\subsection{Técnicas de recolección de datos}

Para recopilar la información de los participantes y responder los objetivos planteados de la investigación, se utilizaron los siguientes instrumentos psicométricos:

\section{a) Time Management Behavior Scale (TMBS)}

Elaborado por Macan et al. (1990). En la presente investigación se utilizó la adaptación al castellano en población universitaria por García y Pérez (2012). El instrumento evalúa la gestión del tiempo académico en alumnos de educación superior, cuyo proposito es determinar el uso adecuado o 
inadecuado de la administración del tiempo por parte de los estudiantes. La modalidad de aplicación del test es de manera personal o colectiva y, esta compuesta por cuatro subescalas, las cuales estadísticamente representan el constructo. En este sentido, a continuación se detallan las cuatro subescalas de la escala de comportamiento de gestión del tiempo:

Dimensiones:

Factor I: Establecimiento de objetivos y prioridades, vinculado a la disposición del alumno a elegir y priorizar las demandas académicas. Ítems: 1, 5, 7, 9, 13, 17, 21, 24, 27 y 31 (García \& Pérez, 2012).

Factor II: Herramientas para la gestión del tiempo, relacionado con la utilización de métodos asociados con la administración efectiva del tiempo, como el uso de la agenda, entre otros. Ítems: $3,6,11,14,18,22,25,28,32$, 33 y 34 (García \& Pérez, 2012).

Factor III: Percepción del control del tiempo, vinculado con la frecuencia del estudiante que percibe el control de su tiempo, es decir; la satisfacción de las realizaciones académicas. Ítems: 4, 10, 15, 19 y 29 (García \& Pérez, 2012).

Factor IV: Preferencias por la desorganización, relacionado con el aspecto en que los alumnos organizan o planifican sus tareas y el grado en que 
mantienen un entorno de estudio estructurado. Ítems: 2, 8, 12, 16, 20, 23, 26 y 30 (García \& Pérez, 2012).

La puntación es obtenida por un puntaje total de 34 ítems con cinco alternativas de respuesta, tales como: nunca, pocas veces, algunas veces, habitualmente y siempre; siendo el valor de cada alternativa de $1,2,3,4$ y 5 pertinentemente.

Propiedades psicométricas:

Validez. Realizado por validez de constructo a través del análisis factorial exploratorio, en donde se evidencia que el $\mathbf{4 2 . 9 3 \%}$ de la varianza representa el constructo (García \& Pérez, 2012).

Fiabilidad. Realizado mediante por consistencia interna de Coeficiente alfa por dimensiones, tales como: factor I $\alpha=.84$, factor II $\alpha=.79$, factor III $\alpha=$ .71 y factor IV $\alpha=.72$; valores aceptables (García \& Pérez, 2012).

b) Utrecht Work Engagement Student - Scale (UWES-17)

Construido por Schaufeli y Bakker (2003) versión para estudiantes. Adaptado y traducido en población universitaria de latinoamerica por Medrano et al. (2015). El instrumento evalúa el compromiso académico, es decir, el funcionamiento óptimo de los estudiantes en sus instituciones educativas. La modalidad de aplicación del test es de carácter personal o 
colectiva $y$, estadísticamente se encuentra representada por tres subescalas. A continuación se detallan las tres subescalas:

Dimensiones:

Factor I: Vigor, vinculado con la aspiración y la disposición de emplear mayor ahínco en las actividades académicas que se ejecutan y la insistencia en resolverlas incluso cuando son dificiles de procesar. Ítems: 1, 4, 8, 12, 15 y 17 (Carrasco, De la corte \& León, 2010).

Factor II: Dedicación, vinculada con el compromiso estundiantil, es decir; la manifestación de altos niveles de rendimiento que conllevan emociones positivas, los cuales contribuyen a sus actividades académicas y condiciones de salud personal. Ítems: 2, 5, 7, 10 y 13.

Factor III: Absorción, relacionada con la entrega y disposición de un individuo vinculado a sus actividades académicas, es decir; el sujeto percibe sensaciones de placer al realizar sus funciones asignadas e incluso el tiempo carece de importancia. Ítems: 3, 6, 9, 11, 14 y 16.

La puntuación es obtenida a través de un puntaje total de 17 ítems con siete opciones de respuestas, las cuales son: nunca, casi nunca, algunas veces, regularmente, bastantes veces, casi siempre y siempre; siendo el valor de cada alternativa de $0,1,2,3,4,5$ y 6 oportunamente. 
Propiedades psicometricas:

Validez: Realizado a través de la validez de constructo mediante analísis factorial exploratorio y confirmatorio, evidenciando óptimos resultados. En ese sentido, se realizó el tipo de validez convergente con una prueba de satisfacción académica $(r=.40, p<.01)$ y la escala de afecto posisitvo y negativo $(r=.38, p<.01)$ (Medrano, Moretti \& Ortiz, 2015).

Fabilidad: Realizado mediante por consistencia interna de Coenficiente alfa por dimensiones, tales como: vigor $\alpha=.79$, dedicación $\alpha=.74$, absorción $\alpha$ $=.81$. (Medrano, Moretti \& Ortiz, 2015).

Finalmente, respecto al estudio, se realizó análisis de fiabilidad y validez para corroborar si los instrumentos utilizados miden lo que pretenden medir. En ese sentido, respecto a la fiabilidad, se empleó la prueba de consistencia interna a través del coeficiente omega $(\omega)$, cuyos valores deberán superar el .70 (Campo \& Oviedo, 2008). Asimismo, respecto a la validez, se realizó validez basada en la estructura interna, mediante el análisis factorial confirmatorio (AFC). (Ver anexo 3)

\subsection{Técnicas estadísticas para el procesamiento de la información}

Luego de recopilar la información mediante los instrumentos psicométricos utilizados, los datos fueron digitados en una hoja de cálculo de Excel. Posteriormente, se implementó aquella base de datos al software estadístico 
rstudio versión 4.0.2 (R Core Team, 2019). En ese sentido, para abordar los objetivos propuestos de la investigación, se indagó en principio la distribución de normalidad de los datos utilizando la prueba de Kolmogorov Smirnov Lilliefors (KSL) debido a que la muestra es > 50 (Pedrosa, Juarros, Robles, Basteiro, \& García, 2015), con el objetivo de averiguar qué técnicas estadísticas se deberían utilizar. Por lo tanto, de acuerdo a los resultados de la distribución de normalidad, para el análisis inferencial se utilizó las técnicas no paramétricas.

Por ello, se utilizó la prueba estadística de correlación rho de Spearman $\left(r_{s}\right)$ para conocer si la relación es positiva o negativa. Asimismo, se utilizó el tamaño del efecto para describir la magnitud de las correlaciones. Respecto a la estadística descriptiva, se ejecutó las medidas de frecuencia y porcentaje para la puntuación total y según dimensiones de las variables de estudio.

Por último, los paquetes utilizados fueron el tidyverse (Wickham et al., 2019), nortest (Gross \& Ligges, 2015), statsExpression (Patil, 2020), psych (Revelle, 2018), lavaan (Rosseel, 2012), semPlot (Epskamp, 2015), readxl (Wickham \& Bryan, 2019), ggstatsplot (Patil, 2018) y ggplot2 (Wickham, 2009).

\subsection{Aspectos éticos}

En primera instancia, se redactó una carta, solicitando la aprobación del presente estudio dirigida hacia el director de la escuela académica profesional de psicología de la universidad privada norbert wiener ubicada en el distrito de Cercado de Lima para la ejecución del proyecto de investigación. En ese 
sentido, de acuerdo a la aprobación de la solicitud, se informó al personal administrativo, docentes y alumnos el motivo de la investigación y los fines pertinentes del uso de los instrumentos psicométricos. Asimismo, se reservó los datos personales y la autonomía de los participantes, puesto que la participación en la investigación no fue obligatoria.

Por lo tanto, se procedió ingresar a las aulas y brindar las instrucciones de los instrumentos psicométricos para su desarrollo correctamente. Asimismo, luego de la aplicación, se respetó las normas de calificación propuesta por los autores de los instrumentos psicométricos.

Finalmente, los resultados permitieron conocer a profundidad el comportamiento de la gestión del tiempo que disponen los alumnos de psicología y el compromiso dedicado a los estudios. El beneficio de la investigación brinda recomendaciones a la institución educativa superior y la retroalimentación a los estudiantes y docentes, que a su vez impacta en los patrones sociales del distrito de Cercado de Lima. 


\section{CAPÍTULO IV: RESULTADOS}

En el presente capítulo se exponen los resultados derivados de los análisis estadísticos de la información obtenida a través de la recopilación de los datos, cuya finalidad es brindar respuesta a los objetivos planteados de la investigación.

\section{Tabla 2}

Análisis descriptivo de las variables de estudio

\begin{tabular}{ccc}
\hline & N & $(\%)$ \\
\hline Sexo & 157 & 75.1 \\
Mujer & 52 & 24.9 \\
Hombre & 132 & \\
Grupo etario & 71 & 63.1 \\
17 a 26 años & 4 & 34.0 \\
27 a 35 años & 2 & 1.9 \\
36 a 44 años & & 1.0 \\
45 a más & 50 & 24.0 \\
Gestión del tiempo & 109 & 52.0 \\
Bajo & 50 & 24.0 \\
Moderado & & \\
Alto & 49 & 23.0 \\
Bajo & 115 & 55.0 \\
Compromiso académico & 45 & 22.0 \\
Moderado & & \\
Alto & &
\end{tabular}

Fuente: elaboración propia (2019) 
En la tabla 2 se evidencia las características sociodemográficas y los niveles de frecuencia de las variables de estudio. Por lo tanto, respecto al sexo de los participantes, el $75.1 \%$ de la muestra representan las mujeres y el $24.9 \%$ los hombres. Asimismo, de acuerdo a la edad, se puede observar que el $63.1 \%$ pertenece al grupo etario de 17 a 26 años, el $34 \%$ pertenece al grupo etario de 27 a 35 años, el $1.9 \%$ pertenece al grupo etario de 36 a 44 años y el $1 \%$ se encuentra entre los 45 años a más. Por último, se evidencia que los estudiantes de psicología presentan una frecuencia media de gestión del tiempo (52\%) y compromiso académico (55\%) asociado a los estudios.

\section{Tabla 3}

Kolmogorov Smirnov de gestión del tiempo y compromiso académico

\begin{tabular}{cll}
\hline Estadístico & KSL & P \\
\hline Gestión del tiempo & 0.065 & 0.029 \\
Compromiso académico & 0.084 & 0.001 \\
Vigor & 0.081 & 0.001 \\
Dedicación & 0.157 & 0.001 \\
Absorción & 0.085 & 0.001 \\
\hline
\end{tabular}

Fuente: elaboración propia (2019)

En la tabla 3, se evidencia la prueba de distribución normal con el estadístico de Kolmogorov Smirnov Lilliefors (KSL). Asimismo, se evidencia que el coeficiente de KSL es significativo $p<.000$. Evidenciando que los datos procedentes de la gestión del tiempo y compromiso académico no se ajustan a una distribución normal. Por lo tanto, para contestar los objetivos de la investigación, se emplearán las pruebas estadísticas no paramétricas para el análisis de los resultados. 

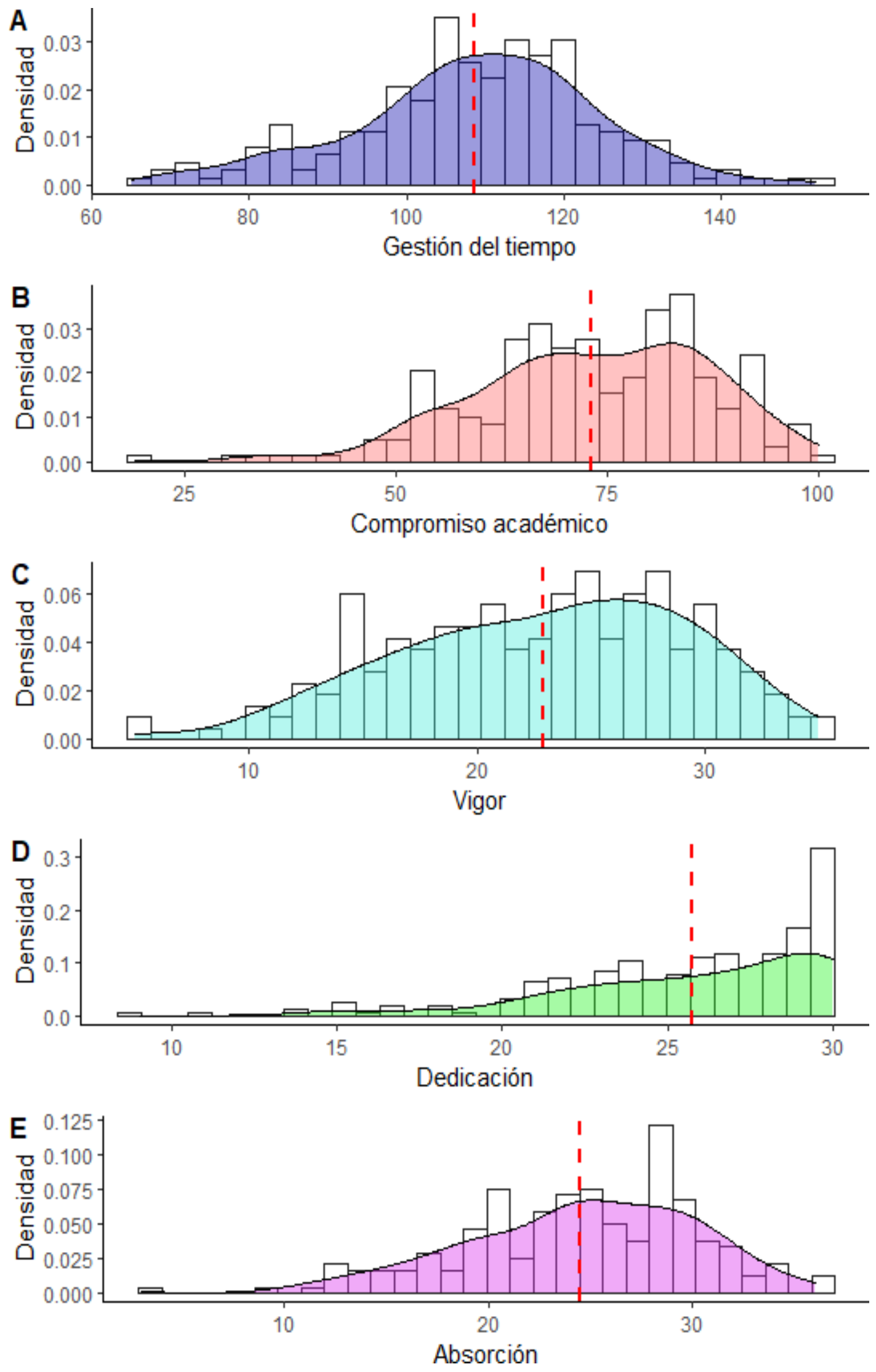

Figura 1. Histograma de gestión del tiempo y compromiso académico 


\section{Tabla 4}

Relación entre gestión del tiempo y compromiso académico

\begin{tabular}{lcc}
\hline & $\begin{array}{c}\text { Compromiso } \\
\text { académico }\end{array}$ & Tamaño del efecto \\
\hline Gestión del tiempo & $.304^{* *}$ & Mínimo \\
${ }^{* *} \mathrm{p}<.001$ & &
\end{tabular}

En la tabla 4, se evidencia el análisis inferencial de correlación entre la gestión del tiempo y el compromiso académico de los estudiantes de la carrera profesional de psicología. Se aprecia que existe una correlación positiva y estadísticamente significativa $\left(r_{s}=.304^{* *}, p=.001\right)$, aunque el tamaño del efecto es mínimo. Por lo tanto, se puede manifestar que a mayor gestión del tiempo mayor compromiso académico de los estudiantes de psicología.

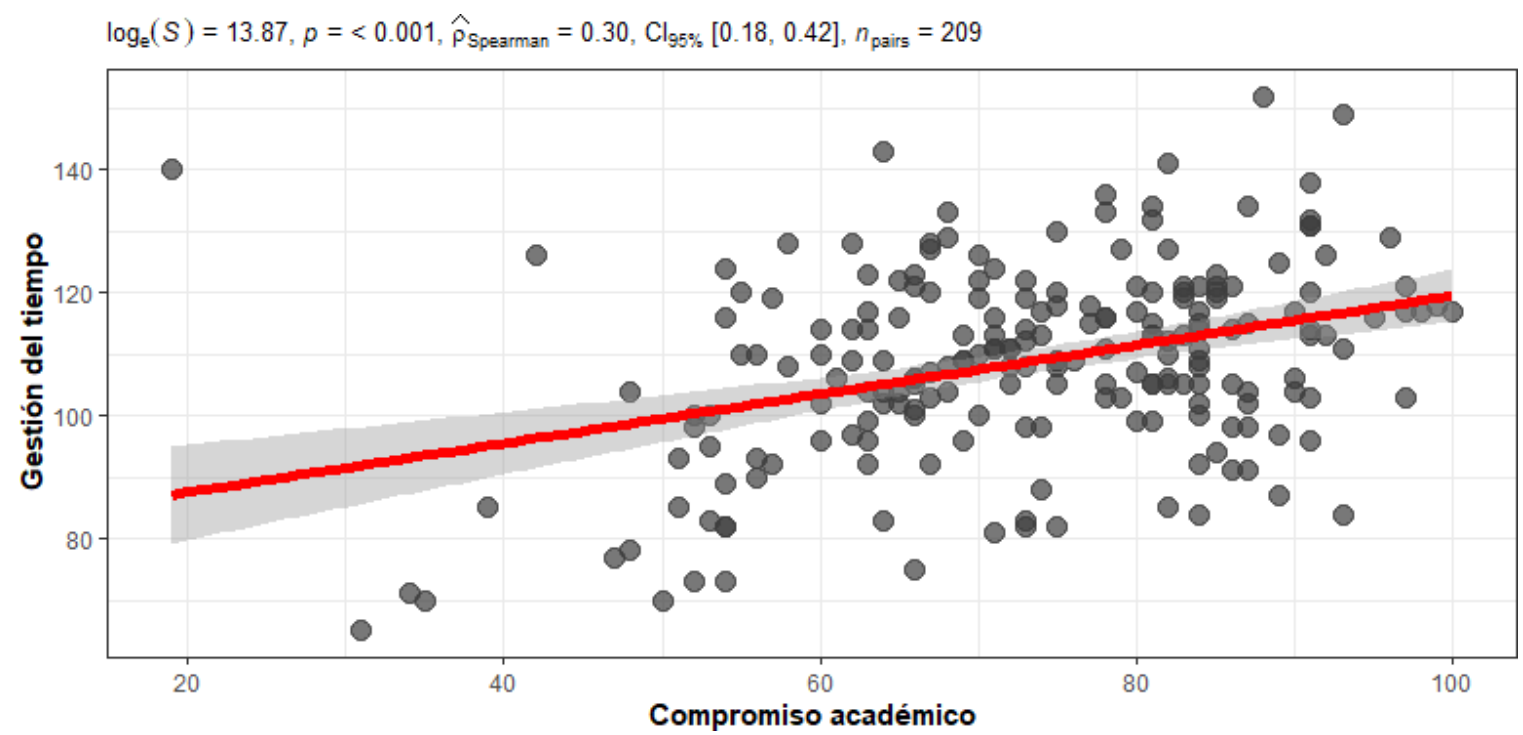

Figura 2. Diagrama de dispersión entre la gestión del tiempo y el compromiso académico de los estudiantes de psicología de la universidad privada norbert wiener, 2019. 


\section{Tabla 5}

Relación entre gestión del tiempo y dimensión de compromiso académico, expresado en vigor

\section{Vigor Tamaño del efecto}

Gestión del tiempo $\quad .378^{* *} \quad$ Mínimo

${ }^{* *} p<.001$

En la tabla 5, se reporta el análisis inferencial de correlación entre la gestión del tiempo y la dimensión de compromiso académico expresado en vigor de los estudiantes de la carrera profesional de psicología. Se aprecia que existe una correlación positiva y estadísticamente significativa $\left(r_{s}=.378^{* *}, p=.001\right)$, aunque el tamaño del efecto es mínimo. En ese sentido, se puede indicar que a mayor gestión del tiempo mayor vigor en los estudiantes de psicología.

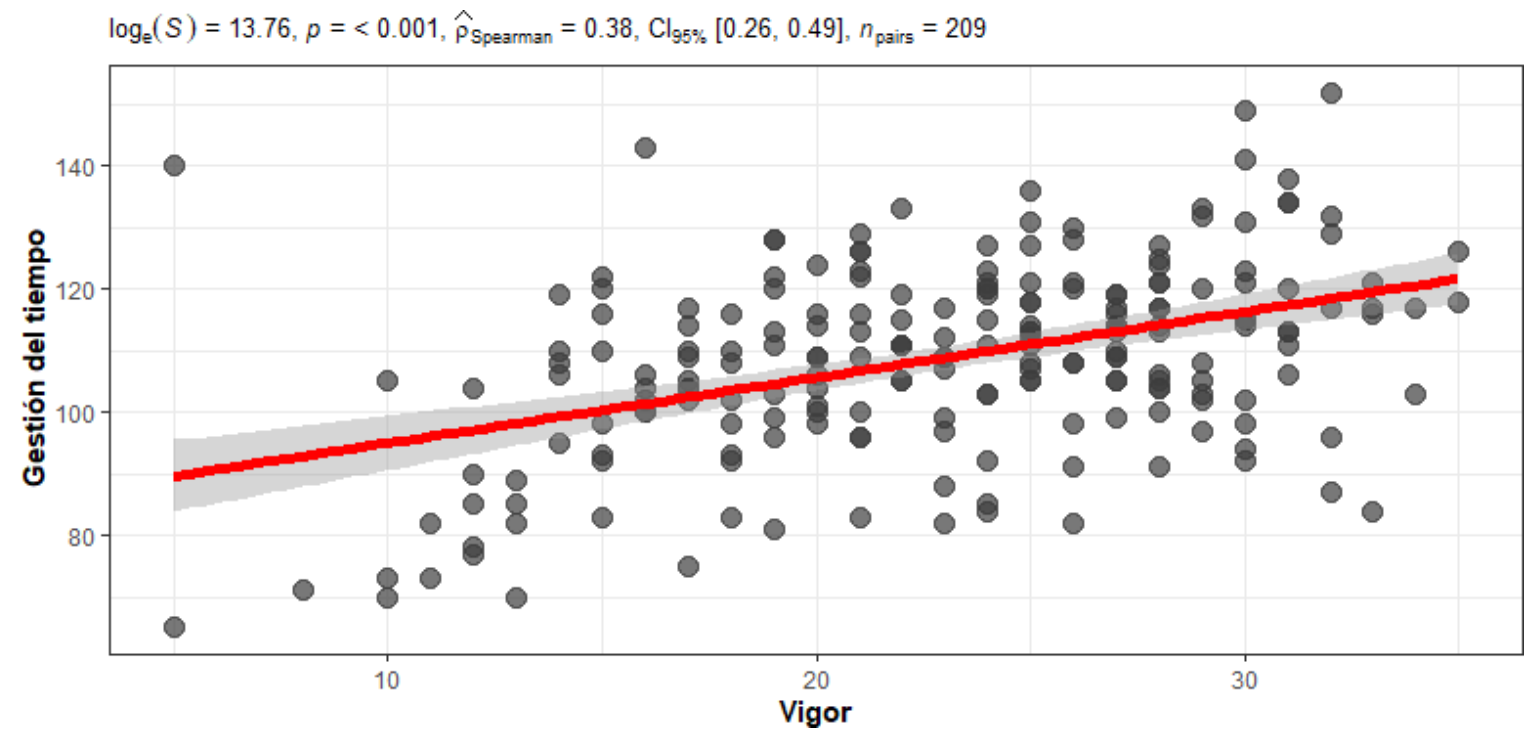

Figura 3. Diagrama de dispersión entre la gestión del tiempo y la dimensión de compromiso académico expresado en vigor de los estudiantes de psicología de la universidad privada norbert wiener, 2019. 


\section{Tabla 6}

Relación entre gestión del tiempo y dimensión de compromiso académico, expresado en dedicación

\section{Dedicación Tamaño del efecto}

$\begin{array}{lll}\text { Gestión del tiempo } & .109 & \text { No efecto }\end{array}$

${ }^{* *} p<.001$

En la tabla 6, se reporta el análisis inferencial de correlación entre la gestión del tiempo y la dimensión de compromiso académico expresado en dedicación de los estudiantes de la carrera profesional de psicología. Se evidencia que no existe correlación puesto que los resultados no son estadísticamente significativos $\left(r_{s}=\right.$ $.109, p=.117)$, revelando también ningún efecto. Por lo tanto, se concluye que la gestión del tiempo no se correlaciona con la dimensión dedicación del compromiso académico.

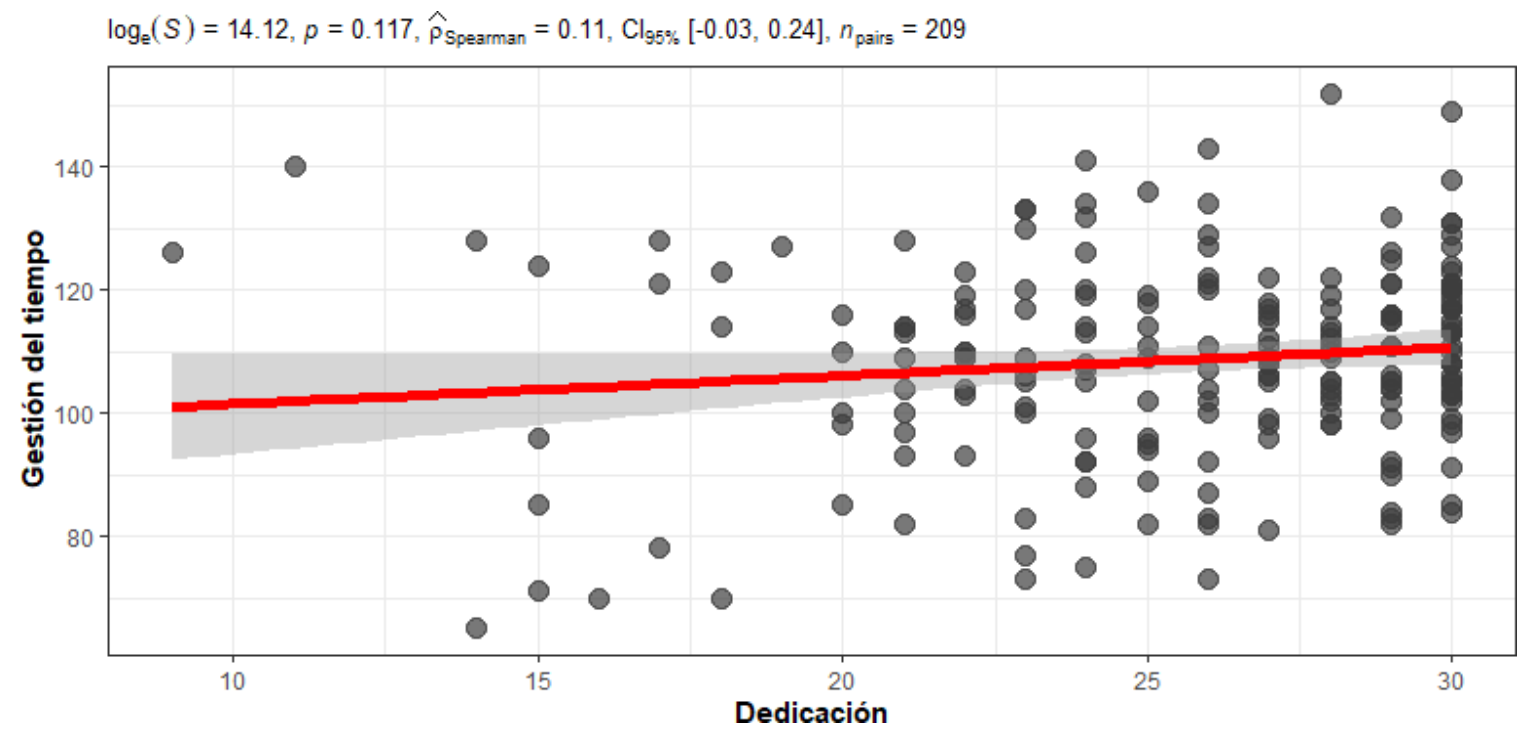

Figura 4. Diagrama de dispersión entre la gestión del tiempo y la dimensión de compromiso académico expresado en dedicación de los estudiantes de psicología de la universidad privada norbert wiener, 2019. 


\section{Tabla 7}

Relación entre gestión del tiempo y dimensión de compromiso académico, expresado en absorción

\section{Absorción Tamaño del efecto}

Gestión del tiempo $.286^{* *}$ Mínimo

$\overline{{ }^{* \star} p<.001}$

En la tabla 7, se evidencia el análisis inferencial de correlación entre la gestión del tiempo y la dimensión de compromiso académico expresado en absorción de los estudiantes de la carrera profesional de psicología. Los resultados señalan que existe una correlación positiva y estadísticamente significativa $\left(r_{s}=.286^{* *}, p=.001\right)$, aunque con un tamaño del efecto mínimo. En ese sentido, se concluye que a mayor gestión del tiempo mayor absorción de los estudiantes de psicología.

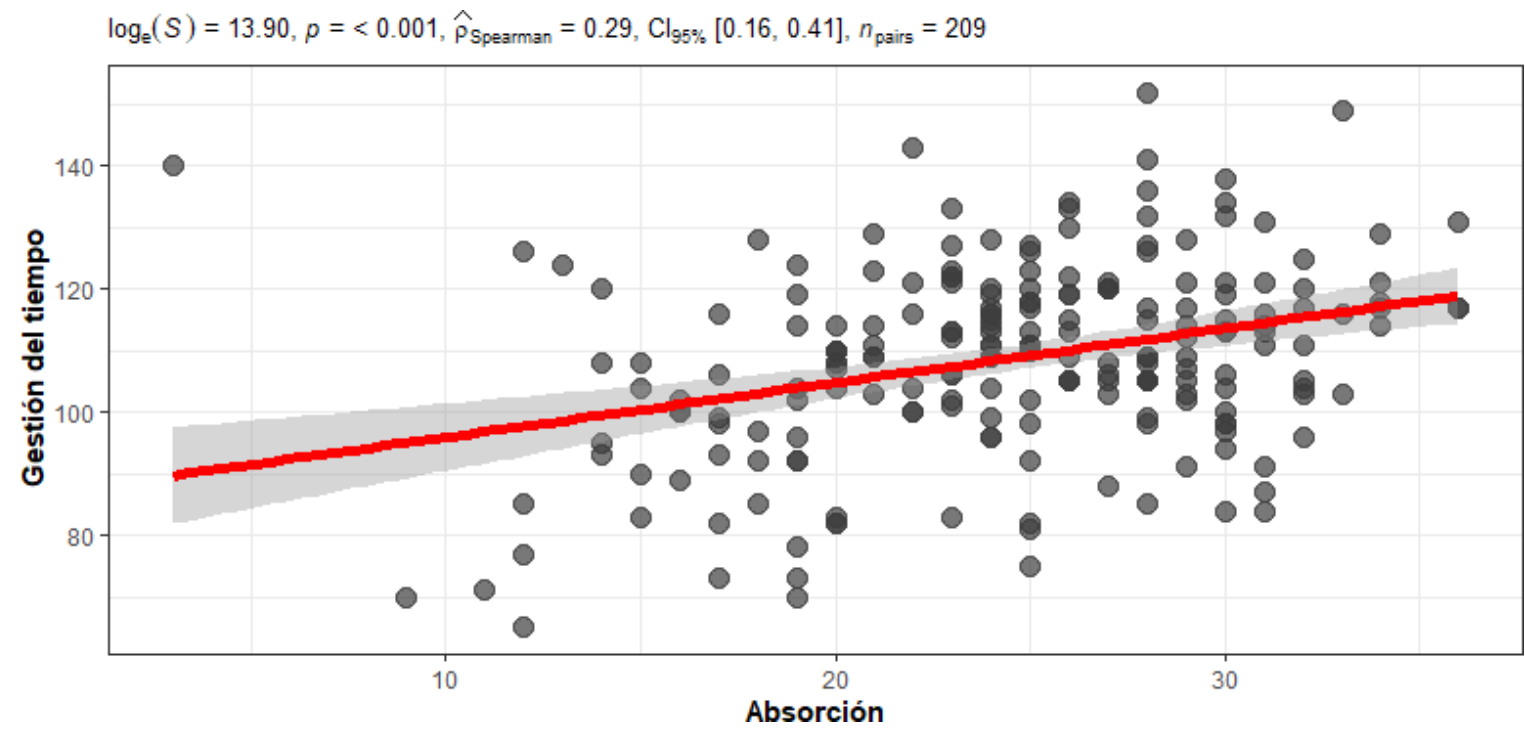

Figura 5. Diagrama de dispersión entre la gestión del tiempo y la dimensión de compromiso académico expresado en absorción de los estudiantes de psicología de la universidad privada norbert wiener, 2019. 


\section{Tabla 8}

Descripción de gestión del tiempo de manera general y según dimensiones en los estudiantes de psicología

\begin{tabular}{|c|c|c|c|c|c|c|c|c|c|c|}
\hline & \multicolumn{2}{|c|}{$\begin{array}{c}\text { Establecimiento } \\
\text { de objetivos y } \\
\text { prioridades }\end{array}$} & \multicolumn{2}{|c|}{$\begin{array}{l}\text { Herramientas } \\
\text { para la gestión } \\
\text { del tiempo }\end{array}$} & \multicolumn{2}{|c|}{$\begin{array}{l}\text { Percepción } \\
\text { del control } \\
\text { del tiempo }\end{array}$} & \multicolumn{2}{|c|}{$\begin{array}{l}\text { Preferencias por la } \\
\text { desorganización }\end{array}$} & \multicolumn{2}{|c|}{$\begin{array}{c}\text { Gestión } \\
\text { del tiempo }\end{array}$} \\
\hline & $\bar{f}$ & $\%$ & $\bar{f}$ & $\%$ & $\bar{f}$ & $\%$ & $\bar{f}$ & $\%$ & $\bar{f}$ & $\%$ \\
\hline Bajo & 50 & 24 & 49 & 23 & 48 & 23 & 49 & 23 & 50 & 24 \\
\hline Moderado & 108 & 52 & 113 & 54 & 123 & 59 & 109 & 52 & 109 & 52 \\
\hline Alto & 51 & 24 & 47 & 23 & 38 & 18 & 51 & 25 & 50 & 24 \\
\hline Total & 209 & 100 & 209 & 100 & 209 & 100 & 209 & 100 & 209 & 100 \\
\hline
\end{tabular}

Fuente: elaboración propia (2019)

Gestión del tiempo

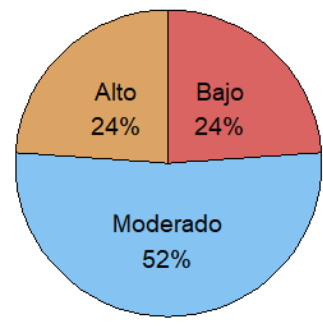

Percepción del control del tiempo

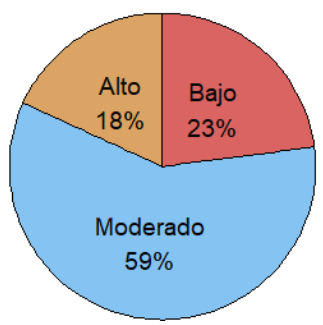

Establecimiento de objetivos y prioridades

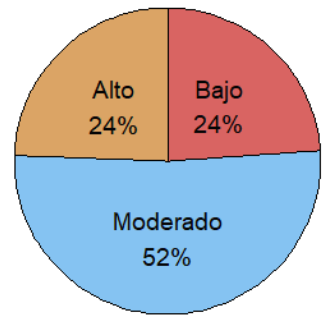

Preferencias por la desorganización

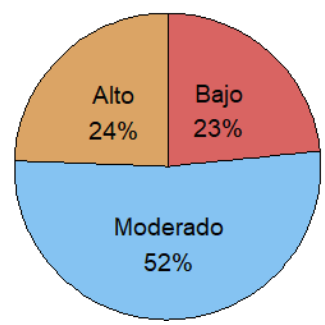

Figura 6. Porcentaje de la gestión del tiempo de manera general y según dimensiones de los estudiantes de psicología de la universidad privada norbert wiener, 2019.

En la tabla 8 y figura 5, se presenta la descripción de la gestión del tiempo de manera general y según dimensiones en los estudiantes de la carrera profesional de psicología. Los resultados muestran que la prevalencia de los estudiantes de psicología respecto a la gestión del tiempo de manera general es moderada $52 \%$, 
seguida de un $24 \%$ de nivel bajo. No obstante, se evidencia un $24 \%$ de los estudiantes que se encuentran en un nivel alto de gestionar su tiempo.

Respecto a las dimensiones, se aprecia que los estudiantes de psicología presentan un nivel moderado de preferencia por la desorganización y establecimiento de objetivos y prioridades con un 52\%. Asimismo, un $54 \%$ de nivel moderado de herramientas para la gestión del tiempo y un 59\% de nivel moderado respecto a la percepción del control del tiempo.

\section{Tabla 9}

Descripción de compromiso académico de manera general y según dimensiones de los estudiantes de psicología

\begin{tabular}{|c|c|c|c|c|c|c|c|c|}
\hline & \multicolumn{2}{|c|}{ Vigor } & \multicolumn{2}{|c|}{ Dedicación } & \multicolumn{2}{|c|}{ Absorción } & \multicolumn{2}{|c|}{ Compromiso académico } \\
\hline & $\bar{f}$ & $\%$ & $\bar{f}$ & $\%$ & $\bar{f}$ & $\%$ & $\bar{f}$ & $\%$ \\
\hline Bajo & 45 & 22 & 42 & 20 & 42 & 20 & 49 & 26 \\
\hline Moderado & 122 & 58 & 119 & 57 & 123 & 59 & 115 & 53 \\
\hline Alto & 42 & 20 & 48 & 23 & 44 & 21 & 45 & 22 \\
\hline Total & 209 & 100 & 209 & 100 & 209 & 100 & 209 & 100 \\
\hline
\end{tabular}

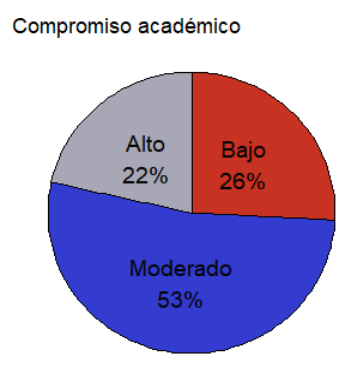

Dedicación

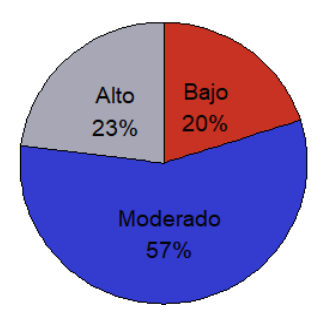

Vigor

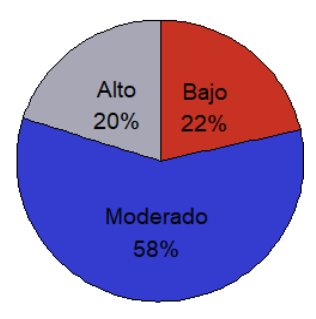

Absorción

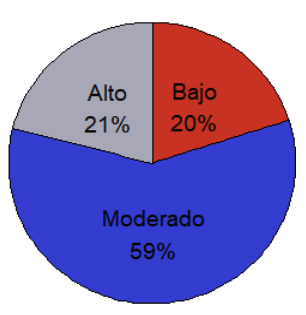


Figura 7. Porcentaje del compromiso académico de manera general y según dimensiones de los estudiantes de psicología de la universidad privada norbert wiener, 2019.

En la tabla 9 y figura 6, se presenta la descripción del compromiso académico de manera general y según dimensiones en los estudiantes de la carrera profesional de psicología. En este sentido, los resultados indican que la prevalencia de compromiso académico de manera general presenta un $53 \%$ de nivel moderado, seguido de un $26 \%$ de nivel bajo. Sin embargo, existe un $22 \%$ de los estudiantes que se encuentren en un nivel alto de compromiso académico.

Respecto a las dimensiones, se aprecia que los estudiantes de psicología presentan en mayor medida, un $59 \%$ de nivel moderado respecto a la dimensión de absorción. No obstante, existe un $58 \%$ de nivel moderado de vigor y un $57 \%$ de nivel moderado asociado a la dedicación de los estudios. 


\section{CAPÍTULO V: DISCUSIÓN}

Luego de procesar los análisis descriptivos e inferenciales para brindar respuestas a los problemas planteados en la investigación. En el presente capítulo se analizan y discuten los hallazgos obtenidos, comparándolos con los reportes de análisis estadísticos de diferentes estudios nacionales e internacionales.

Asimismo, es preciso indicar que la investigación se desarrolló con el objetivo de indagar si existe relación entre la gestión del tiempo y el compromiso académico en estudiantes de psicología de la universidad privada norbert wiener, matriculados en el ciclo académico 2019-II. Los estudiantes de psicología que participaron en la investigación eran de ambos sexos, de diversos ciclos y de ambos turnos disponibles (mañana y noche).

Los datos de la presente investigación no se ajustan a una distribución normal (Tabla 3). Por tal motivo, para realizar los análisis inferenciales se recurrió a las pruebas estadísticas no paramétricas, cuyo supuesto principal es que lo datos no se ajusten a una distribución normal.

En la tabla 4, se dispone a analizar estadísticamente el objetivo general de la investigación, el cual indica determinar la relación entre gestión del tiempo y 
compromiso académico en estudiantes de psicología de la universidad privada norbert wiener. Para responder el objetivo general se utilizó la prueba estadística no paramétrica Rho de Spearman. Los resultados indican que existe relación positiva y estadísticamente significativa. En ese sentido, cuanto mayor es la gestión del tiempo, mayor es el compromiso académico. Por lo tanto, se acepta la hipótesis general, la cual señala que la gestión del tiempo y el compromiso académico están relacionados de manera directa y estadísticamente significativa.

En esta misma línea, los resultados concuerdan con el estudio de Urco (2019) el cual revela que la gestión del tiempo y la autorregulación de actividades, se correlacionan de manera directa y estadísticamente significativa $(r=.113, p<.000)$ manifestando que una mayor organización promueve un mayor alcance de logros académicos, compromiso y bienestar. Del mismo modo, Alcántara (2019) mediante un análisis de regresión, indica que un incremento del nivel de bienestar, disminuye la intensidad de estrés, prediciendo un elevado compromiso en los estudiantes universitarios. Resultados similares señala Fernández (2018) el cual expresa que a mayor índice de estímulos estresores menores serán los niveles de compromiso.

Por otro lado, como primer objetivo específico se planteó determinar la relación entre la gestión del tiempo y el compromiso académico expresado en vigor en estudiantes de psicología. Los hallazgos indican que existe una correlación positiva y estadísticamente significativa con la dimensión vigor del compromiso académico, aunque con un tamaño del efecto mínimo. Por lo tanto, los resultados permiten aceptar la primera hipótesis específica, la cual señala que cuanto mayor es la evidencia de gestión del tiempo mayor también es él compromiso académico vinculado con el vigor en estudiantes de psicología de la universidad privada norbert wiener (Tabla 5). 
Vinculado con lo anterior, Fernández (2018) sostiene que a mayor frecuencia de actividades en el aula, menores serán los niveles de vigor y dedicación. Puesto que el modelo de enseñanza del docente (personalidad, didáctica, entre otros) y la competencia académica entre los asistentes, puede ser un componente de estrés para algunos estudiantes. Provocando desinterés en las tareas individuales, grupales, participación en clase e incluso la inasistencia a la institución educativa. No obstante, Gutiérrez, Tomás y Alberola (2018) indican que el apoyo del docente se correlaciona de manera positiva y estadísticamente significativa con la energía $\left(\mathrm{r}=.53^{* *}, \mathrm{p}<.01\right)$, dedicación $\left(\mathrm{r}=.48^{* *}, \quad \mathrm{p}<.01\right)$ y absorción $\left(\mathrm{r}=.48^{* *}, \quad \mathrm{p}<.01\right)$. Manifestando que el desarrollo de la autonomía en los estudiantes favorece en gran medida el compromiso, es decir, el estudiante se involucra con sus estudios y el proceso de aprendizaje, mejora su rendimiento y se identifica con la institución educativa.

Del mismo modo, como segundo objetivo específico se planteó determinar la relación entre la gestión del tiempo y el compromiso académico expresado en dedicación en estudiantes de psicología. Los análisis señalan que no existe relación puesto que no son estadísticamente significativo p>.05 con la dimensión dedicación del compromiso académico. En ese sentido, el hallazgo concede rechazar la segunda hipótesis específica, la cual indica que cuanto mayor es la evidencia de gestión del tiempo mayor también es él compromiso académico vinculado con la dedicación en estudiantes de psicología de la universidad privada norbert wiener (Tabla 6).

En efecto, un comportamiento adecuado del tiempo no necesariamente involucra mayor dedicación a los estudios por parte de los estudiantes universitarios. Asimismo, la participación en actividades académicas de la población universitaria 
peruana, solo representa el $39,5 \%$ a nivel nacional, siendo un porcentaje muy bajo. Sin embargo, es necesario indicar que las mujeres $(25,1 \%)$ dedican más tiempo a las actividades académicas a comporación de los hombres (24,9\%) (INEI, 2010).

Oriol, Mendoza, Covarrubias y Molina (2017) señalan que la dedicación o la autoeficacia del estudiante, pronostica mayor el nivel de compromiso académico e incluso mejora el rendimiento. No obstante, el compromiso será mayor o menor, de acuerdo a la personalidad del estudiante. Como también del contexto académico, mediante el apoyo de los docentes, las evaluaciones continuas, los ambientes disponibles, la enseñanza reflexiva y el trato horizontal (Daura, 2015).

Por otro lado, el tercer objetivo específico consiste en determinar la relación entre la gestión del tiempo y el compromiso académico expresado en absorción en estudiantes de psicología. Los hallazgos señalan que existe correlación positiva y estadísticamente significativa con la dimensión absorción del compromiso académico. Por lo tanto, los resultados permiten aceptar la tercera hipótesis específica de la investigación, la cual menciona que cuanto mayor es la evidencia de gestión del tiempo mayor también es él compromiso académico vinculado con la absorción en estudiantes de psicología de la universidad privada norbert wiener (Tabla 7).

Igualmente, Gaeta y Cavazos (2016) indican que los estudiantes con promedio más alto dedican mayor tiempo a los estudios. Los estudiantes se sienten más seguros y confiados para afrontar o gestionar su aprendizaje. Del mismo modo, Pilares (2017) señala que los estudiantes absorbidos por sus estudios, también planifican sus actividades e incluso elaboran un plan de vida. Los estudiantes presentan 
mayor predisposición a los estudios, lo cual concede un alto rendimiento académico y satisfcacción personal.

En esta misma línea, el cuarto objetivo específico fue describir la gestión del tiempo de manera general y según dimensiones que muestran los estudiantes de psicología. Los hallazgos revelan que los estudiantes de psicología presentan un nivel moderado general de la gestión del tiempo y como también respecto a sus dimensiones. No obstante, los estudiantes de psicología presentan mayor percepción del control del tiempo a comparación del establecimiento, herramientas y preferencias (Tabla 8). Es decir, los estudiantes elucubran sobre el comportamiento del tiempo que disponen y elaboran estrategias pertinentes (horario, anotaciones, entre otros) para ordenar y verificar las actividades estudiantiles. Utiliza las estrategias para orientar y modelar su comportamiento, asumiendo un mayor control del tiempo.

Los resultados concuerdan con la investigación de Mohamadkhani et al. (2017) quienes reportan niveles moderados de habilidades de gestión del tiempo (49\%) de los alumnos universitarios. Asimismo, mencionan que existe una relación significativa entre gestión del tiempo y motivación $(r=.279, p<.001)$, siendo un factor relevante para el comportamiento adecuado del tiempo.

Finalmente, el quinto objetivo específico de la investigación propuso describir el compromiso académico de manera general y según dimensiones que muestran los estudiantes de psicología. Los hallazgos apuntan que la mayor prevalencia en los estudiantes de psicología se encuentra en la categoría moderada general y factorial del compromiso académico. No obstante, en los estudiantes de psicología prevalece mayormente la absorción que se encuentra vinculada con la disposición 
del estudiante a realizar las tareas académicas que competen a su programa de estudios. El estudiante evidencia placer y gusto al desarrollar las tareas asignadas e incluso el tiempo no es un factor que impida su finalización (Tabla 9).

La literatura científica señala que el tiempo es un recurso valioso (Huamán, 2019) y que el uso efectivo del tiempo, promueve en el estudiante independencia y autonomía (Marcén \& Martínez, 2012). Aunque existen ladrones del tiempo (Laboris, 2008) como visitas inesperadas, reuniones no programadas, impuntualidad, comunicación inadecuada, encuentros casuales, conversaciones desligadas a las actividades, entre otras. Sustituyendo una actividad planificada con criterio (Bird, 2004). Las investigaciones señalan que una mayor noción de controlar el tiempo se correlaciona de manera postiva y estadísticamente significativa con el promedio general de calificaciones y, que las técnicas de estudio son herramientas indispensables (Adams \& Blair, 2019). Asimismo, se han realizado estudios entre compromiso académico y el hábito parcial del tiempo (Daura, 2018), gestión del tiempo estudiantil en alumnos que se encuentran iniciando sus estudios (Durán \& Pujol, 2013), entre otros.

Los objetivos de la investigación no proponen diferencias entre hombres y mujeres, debido a la ausencia del análisis de invarianza factorial de los instrumentos, el cual garantiza las diferencias entre grupos o variables sociodemográficas (BañosChaparro \& Ramos-Vera, 2020). No obstante, la literatura refiere que las mujeres presentan mayor uso de herramientas para gestionar el tiempo a comparación de los hombres (Monroy, 2017). Aunado a esto, existe evidencia que a mayor estrés menor gestión del tiempo (Monroy, 2017) y mayor gestión del tiempo mayor es el rendimiento académico (Pilares, 2017; Garzón \& Gil, 2017a). 
Lo expuesto en el presente capítulo permite desarrollar nuevas interrogantes respecto a la gestión del tiempo y el compromiso académico. Los estudios citados refieren que promueve mayor autonomía, mayor motivación, mayor rendimiento. Los estudiantes experimentan mayor bienestar y satisfacción, aunque los factores personales y contextuales son aspectos a considerar. Sin embargo, los resultados son asociativos y no causales. Por lo tanto, surge el interés para el desarrollo de próximos estudios la explicación de la gestión del tiempo y el compromiso académico en modelos predictivos, para averiguar qué constructos predicen las variables de estudio de la presente investigación. 


\section{CONCLUSIONES}

1. La investigación revela que cuando los estudiantes presentan mayor gestión del tiempo, a su vez presentan mayor compromiso académico como vigor, dedicación y absorción. Por lo tanto, el comportamiento adecuado de utilizar el tiempo se relaciona con un estado emocional positivo para el proceso de aprendizaje. Siendo una conducta que se mantiene en el tiempo.

2. El estudio señala que los estudiantes que muestran mayor gestión del tiempo, son los que precisamente presentan mayor vigor, por ejemplo: sentirse con

energía durante las clases o las actividades académicas, presentan mayor resistencia física y mental, asisten con entusiasmo a la institución educativa, entre otros.

3. Los estudiantes que presentan mayor gestión del tiempo, no necesariamente presentan mayor dedicación. Puesto que los análisis señalaron que la asociación no es significativa. En este sentido, el comportamiento adecuado de manejar el tiempo no implica una mayor dedicación. Explicando que la dedicación se encuentra expresada mediante una actitud responsable hacia los estudios, el 
compromiso con las tareas asignadas, la motivación e interés hacia los estudios, entre otros.

4. Los estudiantes que presentan mayor gestión del tiempo, presentan a su vez mayor absorción con los estudios, por ejemplo: el estudiante evidencia una mayor concentración durante las clases y el desarrollo de sus tareas académicas, disfruta realizarlas. Asimismo, olvida todo lo que pasa a su alrededor cuando se encuentra estudiando e incluso es difícil que abandone su horario de estudio.

5. La investigación revela que los estudiantes en términos generales presentan moderadamente la gestión de su tiempo. Sin embargo, existe un $24 \%$ de los participantes que muestran un bajo nivel de manejar adecuadamente el tiempo que disponen, por ejemplo: no elaboran una lista de las cosas que tienen que realizar, no establecen metas a corto ni largo plazo, subestiman el tiempo que disponen para desarrollar tareas, no organizan sus actividades con tiempo de anticipación, no marcan fechas ni escriben notas para recordar sus actividades, entre otros.

6. El estudio expone que los estudiantes en términos generales presentan moderadamente su compromiso académico. Sin embargo, existe un $23 \%$ de los participantes que muestran un bajo nivel de compromiso académico; por ejemplo, los estudiantes que se encuentran en aquel porcentaje evidencian desinterés respecto a las tareas académicas asignadas, se sienten débiles cuando se dedican a estudiar o asistir a clases, tienen dificultades para estudiar largos periodos de tiempo, no se sienten orgullosos de su carrera e incluso abandonarlo no tiene mayor significado. 


\section{RECOMENDACIONES}

1. Los análisis sugieren que la gestión del tiempo es una variable significativa para el compromiso académico en los estudiantes de psicología de educación superior. En ese sentido, es indispensable que la escuela académico profesional de psicología en principio realice un estudio preliminar en todos los ciclos de la carrera, con el objetivo de identificar que estudiantes tienen problemas para gestionar su tiempo y a partir de aquello, realizar talleres sobre cómo gestionar el tiempo en la vida universitaria y fortalecer el compromiso académico.

2. Los resultados indican que la gestión del tiempo es importante para el vigor de los estudiantes de psicología. El vigor se entiende como el bienestar físico y mental del estudiante respecto a sus estudios. Por ello, es necesario que los docentes modelen estos mismos comportamientos a sus alumnos durante sus clases y refuercen mediante comentarios positivos o alabanzas, el entusiasmo y la energía que demuestran los alumnos cuando gestionan adecuadamente su tiempo y realizan sus actividades.

3. Se evidenció que la gestión del tiempo no se relacionó con la dedicación. En ese sentido, se sugiere a la escuela académico profesional de psicología en sus 
programas o talleres, enfatizar que el objetivo de manejar adecuadamente el tiempo vinculado a los estudios, es organizar y establecer metas para adquirir una actitud responsable hacia las actividades académicas. Del mismo modo, se recomienda a los docentes que deben proponer trabajos innovadores para motivar a los estudiantes o aceptar las sugerencias de aquellos mismos.

4. Se encontró que la gestión del tiempo se relacionó con la absorción. La absorción se entiende como la capacidad del estudiante para concentrarse en sus actividades académicas y su motivación para realizarlas. En ese sentido, se recomienda a los docentes emplear en sus horas de clases, técnicas conductuales o cognitivas para incrementar la capacidad de concentración de los estudiantes y, como también, reforzar sus logros.

5. Respecto al $24 \%$ de estudiantes de psicología que reportan no manejar adecuadamente su tiempo, se sugiere a la escuela académico profesional de disminuir tal porcentaje mediante la organización de charlas y talleres que brinden los conceptos básicos, su importancia y las herramientas suficientes para abordar esta temática. Además, se sugiere a los docentes ampliar este tema en minutos libres de sus clases y establecer normas de convivencia para un mayor uso del tiempo académico de los estudiantes.

6. Respecto al $23 \%$ de estudiantes de psicología que reportan tener un bajo nivel de compromiso académico, se recomienda a los tutores de cada ciclo averiguar en principio si existen problemas familiares o económicos que estén interfiriendo en aspectos académicos del estudiante. Asimismo, brindar charlas o asesoría personalizada sobre las dificultades en algunas asignaturas, problemas de inasistencia, etcétera. 


\section{FUENTES DE INFORMACIÓN}

Adams, R. V., \& Blair, E. (2019). Impact of time management behaviors on undergraduate engineering students' perfomance. SAGE Open, 9(1), 1-11. doi:10.1177/2158244018824506

Ajzen, I. (1991). The theory of planned behavior. Organizational behavior and human decision processes, 50, 179-211.

Alcántara, K. (2019). Estudiantes de alto rendimiento: Compromiso académico, estrés académico y bienestar. Lima: Pontificia universidad católica del perú.

Arguedas, N. (2010). Involucramiento de las estudiantes y los estudiantes en el proceso educativo. Revista iberoamericana sobre calidad, eficacia y cambio en educación, 8(1), 63-78.

Ato García, M., \& Vallejo Seco, G. (2015). Diseños de investigación en psicología. Madrid: Pirámide.

Bakker, A., \& Demerouti, E. (2013). La teoría de las demandas y los recursos laborales. Revista de psicología del trabajo y de las organizaciones, 29(3), 107-115. doi:10.5093/tr2013a16

Bakker, A., Demerouti, E., \& Euwema, M. (2005). Job resources buffer the impact of job demands on burnout. Journal of occupational healt psychology, 10 , 170-180. doi:10.1037/1076-8998.10.2.170

Baños-Chaparro, J. (2020). Uso de Redes Sociales y Sintomatología Depresiva en

Estudiantes Universitarios. Eureka, 17(2), 293-308.

https://www.psicoeureka.com.py/sites/default/files/articulos/eureka-17-2-

13_0.pdf 
Baños-Chaparro, J. (2020). Gestión del tiempo académico en estudiantes de psicología: un estudio comparativo. Yachay - Revista Científico Cultural, 9(1), 543-547. https://doi.org/10.36881/yachay.v9i01.221

Baños-Chaparro, J. (2020). Uso de redes sociales y sintomatología depresiva en estudiantes de una universidad privada de Lima, 2019. Tesis de licenciatura, Universidad Privada Norbert Wiener, Lima. http://repositorio.uwiener.edu.pe/xmlui/handle/123456789/3595

Baños-Chaparro, J., \& Ramos-Vera, C. (2020). Validez e invarianza según sexo y edad de la Escala Paykel de Ideación Suicida en adolescentes peruanos. Interacciones, 6(1), e225. https://doi.org/10.24016/2020.v6n1.225

Bass, B. (1990). From transactional to transformational leadership: Learning to share the visión. Organizational dynamics, 18(3), 19-31.

Bernal, C. A. (2006). Metodología de la investigación. México: Pearson.

Bird, P. (2004). Como gestionar su tiempo: utilice su tiempo al máximo; aporte orden en su trabajo, sea más eficiente. Barcelona: Ediciones Gestión, S. A.

Britton, B., \& Glynn, S. (1989). Mental management and creativity: A cognitive model of time management for intellectual productivity. En J. Glover, R. Ronning, \& C. Reynolds, Handbook of creativity (págs. 429-440). New York: Plenum Press.

Britton, B., \& Tesser, A. (1991). Effects of time-management practices on college grades. Journal of educational psychology, 83(3), 405-410. doi:10.1037/0022-0663.83.3.405

Bustínduy, I. (2015). La gestión del tiempo. Barcelona, España: Editorial UOC. 
Cable, D., \& Edwards, J. (2004). Complementary and supplementary fit: A theoretical and empirical integration. Journal of applied psychology, 89(5), 822-834.

Campo, A., \& Oviedo, H. (2008). Propiedades psicométricas de una escala: la consistencia interna. Rev Salud Pública, 10(5), 831-839.

Carrasco, A., De la corte, C., \& León, J. (2010). Engagement: un recurso para optimizar la salud psicosocial en las organizaciones y prevenir el burnout y estrés laboral. Revista digital de prevención, 1, 1-22. Obtenido de http://hdl.handle.net/11441/34423

Claessens, B., Van eerde, W., Rutte, C., \& Roe, R. (2004). Planning behavior and perceived control of time at work. Journal of organizational behavior, 25, 93750. doi:10.1108/00483480710726136

Coates, H. (2007). A model of online and general campus-based student engagement. Assessment and evaluation in higher education, 32(2), 121141.

Daura, F. (2015). El estudio del compromiso académico. Panorama general sobre su abordaje. Diálogos pedagógicos(25), 54-75.

Daura, F. (2018). El compromiso académico y la experiencia subjetiva del tiempo en estudiantes de profesorados. Contextos en educación(25), 19-32.

Demerouti, E., Bakker, A., Nachreiner, F., \& Schaufeli, W. (2001). The job demandsresources model of burnout. Journal of applied psychology, 86, 499-512. doi:10.1037//0021-9010.86.3.499 
Durán, E., \& Pujol, L. (2013). Manejo del tiempo académico en jóvenes que inician estudios en la Universidad Simón Bolívar. Revista Latinoamericana de Ciencias Sociales, Niñez y Juventud, 11(1), 93-108.

Epskamp, S. (2015). semPlot: Unified visualizations of structural equation models. $\begin{array}{llll}\text { Structural Equation } \quad \text { Modeling, 22(3), } & \text { 474-83. }\end{array}$ doi:10.1080/10705511.2014.937847

Fernández, A. (2018). Estrés y compromiso académico en estudiantes de una universidad privada de Lima. Tesis inédita de licenciatura, Universidad peruana de ciencias aplicadas, Lima, Perú. doi:10.19083/tesis/625153

Flores Apaza, E. (2017). Relación de la gestión del tiempo y estrés laboral en el personal de la sede administrativa de la Gerencia Regional de Salud Moquegua, enero 2017. Tesis de maestría, Universidad César Vallejo, Lima.

Fredericks, J., Blumenfeld, P., \& Paris, A. (2004). School engagement: potential of the concept, state of the evidence. Review of educational research, 74(1), 59-109.

Gaeta, M., \& Cavazos, J. (2016). Relación entre tiempo de estudio, autorregulación del aprendizaje y desempeño académico en estudiantes universitarios. CPUe. Revista de Investigación Educativa, 23, 142-166. Recuperado el 29 de $\begin{array}{llll}\text { Marzo de } & \text { 2019, de }\end{array}$ http://www.scielo.org.mx/scielo.php?script=sci_arttext\&pid=S1870$53082016000200142 \&$ lng=es\&tlng=es

Gálvez, M., Moreno, B., \& Mingote, J. (2009). El desgaste profesional del médico. Revisión y guía de buenas prácticas. Madrid: Díaz de santos. 
García Marcos, C. J. (2018). La autorregulación de la gestión del tiempo para el aprendizaje en línea en la Formación Profesional española: Efectos de la cuantificación personal del tiempo de estudio. Tesis inédita de doctorado, Universidad de Sevilla, Sevilla, España.

García, R., \& Pérez, F. (2012). Spanish versión of the time management behavior questionnaire for university students. The spanish journal of psychology, 15(3), 1485-1494. doi:10.5209/rev_sjop.2012.v15.n3.39432

García, R., Pérez, F., Talaya, I., \& Martínez, E. (2008). Analysis of time management academic new students in the degree of psychology: predictive capacity and comparative analysis of two assessment instruments. International journal of developmental and educational psychology, 2(1), 245252.

Garzón, A., \& Gil, J. (2017a). Gestión del tiempo en alumnado universitario con diferentes niveles de rendimiento académico. Educação e Pesquisa, 44(0), 1-13. doi:10.1590/s1678-4634201708157900

Garzón, A., \& Gil, J. (2017b). Gestión del tiempo y procrastinación en la educación $\begin{array}{llll}\text { superior. } & \text { Universitas } & \text { Psychologica, } & \text { 16(3), }\end{array}$ doi:10.11144/Javeriana.upsy 16-3.gtpe

Gavala, J., \& Flett, R. (2005). Influential factors moderating academic enjoyment/motivation and psychological well-being for maori university students at massey university. New zealand journal of psychology, 34(1), 5257.

Gómez, J. (2013). Gestión del tiempo como dimensión de la competencia informacional. Anuario ThinkEPI, 7, 28-36. 
Grez Spikin, P. (2018). Efecto de una experiencia de aprendizaje por proyecto sobre el aprendizaje autodirigido, gestión del tiempo y rendimiento académico en estudiantes de tecnología médica de una universidad tradicional. Tesis inédita de doctorado, Universidad de Concepción, Concepción, Chile.

Gross, J., \& Ligges, U. (2015). Nortest: Tests for normality. R package versión 1.04. Obtenido de https://bit.ly/2VBmsDG

Gutiérrez, M., Tomás, J., \& Alberola, S. (2018). Apoyo docente, compromiso académico y satisfacción del alumnado universitario. Estudios sobre educación, 35, 535-555. doi:10.15581/004.34.535-555

Hakanen, J., Bakker, A., \& Schaufeli, W. (2006). Burnout and work engagement among teachers. The journal of school psychology, 43, 495-513. doi:10.1016/j.jsp.2005.11.001

Hobfoll, S., Johnson, R., Ennis, N., \& Jackson, A. (2003). Resource loss, resource gain, and emotional outcomes among inner city women. Journal of personality and social psychology, 84, 632-643. doi:10.1037//00223514.84.3.63judge

Huamán, M. (2019). Uso efectivo del tiempo en las aulas de la institución educativa primaria N³0153 "María natividad salazar aguilar" del distrito de chilca, 2018. Lima: Universidad católica sedes sapientiae.

Instituto de investigación de mercados. (2019). Preocupaciones del mundo. Perú: Ipsos. Recuperado el 10 de Abril de 2019, de https://www.ipsos.com/espe/las-preocupaciones-del-mundo-segun-ipsos-global-dvisor 
Instituto nacional de estadística e informática. (2010). Encuesta nacional de uso del tiempo 2010. Perú: INEI. Recuperado el 10 de Abril de 2019, de https://www.inei.gob.pe/media/MenuRecursivo/publicaciones_digitales/Est/ Lib0960/Libro.pdf

Instituto nacional de estadística e informática. (2017). Perú: Indicadores de educación por departamento, 2007-2017. Perú: INEI. Recuperado el 10 de $\begin{array}{lll}\text { Abril de } & \text { 2019, de }\end{array}$ https://www.inei.gob.pe/media/MenuRecursivo/publicaciones_digitales/Est/ Lib1529/libro.pdf

Kahn, W. (1990). Psychology conditions of personal engagement and disengagement at work. Academy of management jorunal, 33(4), 692-724.

Kline, B. (2005). Principios y práctica de modelado de la ecuación estructural. New York: Guildford Press.

Krause, K., \& Coates, H. (2008). Students' engagement in first-year university. Assessment \& Evaluation in higher education, 33(5), 493-505.

Krause, K., \& Coates, H. (2008). Student's engagement in first-year university. Assessment \& evaluation in higher education, 33(5), 493-505. doi:10.1080/02602930701698892

Kuh, G. (2003). What we're learning about student engagement from NSSE. change, 35(2), 24-32.

Laboris. (2008). Gestión del tiempo: claves para optimizar el tiempo de trabajo. Obtenido de http://www.laboris.net/static/ca_dia_optimizar-tiempo.aspx. 
Lakein, A. (1973). How to get control of your time and your life. New York: New american library.

Law, B. (2005). Experiential learning in the context of educating for a sustainable future: Is it an appropriate pedagogy for shifting teachers' thinking and engaging learners? Research information for teachers, 3, 15-20.

Lay, C., \& Schouwenburg, H. (1993). Trait procrastination, time management, and academic behavior. Journal of social behavior and personality, 8, 647-662.

León, L. (2019). Estudio sobre el uso del tiempo en el aula y su influencia en la calidad de los aprendizajes en la I.E. "San Andrés", distrito de Simón BolívarPasco. Cerro de Pasco: Universidad nacional daniel alcides carrión.

Lewing, K., Xanthopoulou, D., Bakker, A., Dollard, M., \& Metzer, J. (2007). Burnout and connectedness among australian volunteers: A test of the job demandsresources model. Journal of vocational behavior, 71, 429-445. doi:10.1016/j.jvb.2007.07.003

Macan, T. (1994). Time management: Test of a process model. Journal of applied psychology, 79(3), 381-391. doi:10.1037/0021-9010.79.3.381

Macan, T., Shahani, C., Dipboye, R., \& Phillips, A. (1990). College students time management: Correlations with academic performance and stress. Journal of educational psychology, 82(4), 760-768. doi:10.1037/0022-0663.82.4.760

Marcén, M., \& Martínez, N. (2012). Gestión del tiempo de los universitarios: evidencias para estudiantes de primer curso de la universidad de zaragoza. INNOVAR. Revista de ciencias administrativas y sociales, 22(43), 117-130. 
Marín, P., Aranda, F., \& Guzmán, P. (2007). Dirección de grupos y reuniones. Gestión del tiempo. Barcelona: Fundación Rafael Campalans.

Martínez, A., \& Campos, W. (2015). Correlación entre actividades de interacción social registradas con nuevas tecnologías y el grado de aislamiento social en los adultos mayores. Revista méxicana de ingeniería biomédica, 36(3), 181-191.

McMahon, B., \& Portelli, J. (2004). Engagement for what? beyond popular discourses of student engagement. Leadership and policy in schools, 3(1), 59-76.

Medrano, L., Moretti, L., \& Ortiz, A. (2015). Medición del engagement académico en estudiantes universitarios. Revista iberoamericana de diagnóstico y evaluación - e avaliacao psicológica, 2(40), 114-124.

Mohamadkhani, A., Naderi, M., Zagheri, M., Ahmadi, F., \& Hosseini, M. (2017). Relationship between time management skills and anxiety and academic motivation of nursing students in Tehran. Electronic Physician, 9(1), 36783684. doi: $10.19082 / 3678$

Monroy, P. (2017). Estrés académico y manejo de tiempo en estudiantes universitarios de Lima, Perú. Tesis inédita de licenciatura, Pontificia Universidad Católica del Perú, Lima, Perú.

Oriol, X., Mendoza, M., Covarrubias, C., \& Molina, V. (2017). Emociones positivas, apoyo a la autonomía y rendimiento de estudiantes universitarios: el papel mediador del compromiso académico y la autoeficacia. Revista de psicodidáctica, 22(1), 45-53. 
Parra, P., \& Pérez, C. (2010). Propiedades psicométricas de la escala de compromiso académico, UWES-S (versión abreviada), en estudiantes de psicología. Revista de educativa ciencias de salud, 7(2), 128-133.

Patil, I. (2018). ggstatsplot: "ggplot2" Based Plots with Statistical Details. R package versión 0.5.0. doi:https://doi.org/10.5281/zenodo.2074621

Patil, I. (2020). statsExpression: Expressions with Statistical Details. R Package version 0.4.1. Obtenido de https://bit.ly/2yn94KB

Pedrosa, I., Juarros, J., Robles, A., Basteiro, J., \& García, E. (2015). Pruebas de bondad de ajuste en distribuciones simétricas, ¿qué estadístico utilizar? Universitas Psychologica, 14(1), 15-24.

Pilares, R. (2017). Gestión del tiempo y rendimiento académico de los estudiantes de economía, caso: Universidad Andina del Cusco-2016. Tesis inédita de licenciatura, Universidad Andina del Cusco, Cusco, Perú.

Porter, S. (2006). Institutional structures and student engagement. Research in higher education, 47(5), 531-558.

R Core Team. (2019). R: A language and environment for statistical computing [software]. Viena: R Foundation for Statistical Computing. Obtenido de https://bit.ly/325K31r

Revelle, W. (2018). Psych: Procedures for Personality and Psychological Research. $R$ package versión 1.7.3. Evanston: Northwestern University. Obtenido de https://bit.ly/3aKxgFp 
Romero, M., \& Barberà, E. (2013). Identificación de las dificultades de regulación del tiempo de los estudiantes universitarios en formación a distancia. RED, Revista de educación a distancia(38), 1-17.

Rosseel, Y. (2012). lavaan: An R Package for Structural Equation Modeling. Journal of statistical software, 48(2), 36. doi:10.18637/jss.v048.i02

Salanova, M., Bresó, E., \& Schaufeli, W. (2005). Hacia un modelo espiral de las creencias de eficacia en el estudio del burnout y del engagement. Ansiedad y estrés, 11(2-3), 215-231.

Salanova, M., Martínez, I., \& Llorens, S. (2004). Psicología organizacional positiva. En F. Palaci, Psicología organizacional (págs. 349-384). Madrid: PearsonPrentice Hall.

Schaufeli, W. B. (2017). General Engagement: Conceptualization and Measurement with the Utrecht General Engagement Scale (UGES). Journal of Well-Being Assessment, 1, 9-24. doi:https://doi.org/10.1007/s41543-0180013-1

Schaufeli, W., \& Bakker, A. (2003). Utrecht work engagement scale. Holanda: Utrecht university.

Schaufeli, W., Martínez, A., Marques, A., Salanova, M., \& Bakker, A. (2002a). Burnout and engagement in university students: a cross-national study. Journal of Croos, Cultural Phychology, 33, 464-481.

Schaufeli, W., Salanova, M., Gonzalez, V., \& Bakker, A. (2002b). The measurement of engagement and burnout and: A confirmative analytic approach. Journal of happiness studies, 3, 71-92. 
Schuetz, P. (2008). A theory-driven model of community college student engagement. Community college journal of research and practice, 32(4-6), 305-324.

Trowler, V. (2010). Student engagement literature review. Nueva York: The higher education academy.

Umbach, P., \& Wawrzynski, M. (2005). Faculty do matter: the role of college faculty in student learning and engagement. Research in higher education, 46(2), 153-184.

Urco, S. (2019). Relación entre la gestión del tiempo y procrastinación académica en los estudiantes de la facultad de ingeniería de la universidad católica sede sapientiae, filial tarma, 2018. Lima: Universidad católica sedes sapientiae.

Vladimirovich Kirillov, A., Kabdullinovna Tanatova, D., Vasilievich Vinichenko, M., \& Anatolyevich Makushikin, S. (2015). Theory and Practice of TimeManagement in Education. Asian Social Science, 11(19), 193-204. doi:http://dx.doi.org/10.5539/ass.v11n19p193

Wang, W., Kao, C., Huan, T., \& Wu, C. (2010). Free time management contributes to better quality of life: A study of undergraduate students in Taiwan. Journal of happiness studies, 12(4), 561-573. doi:10.1007 / s10902-010-9217-7

Wickham, H. (2009). Ggplot2: Elegant Graphics for Data Analysis. Springer. doi:10.1007/978-3-319-24277-4

Wickham, H., \& Bryan, J. (2019). readxl: Read excel files. Obtenido de https://CRAN.R-project.org/package=readxl 
Wickham, H., Avrick, M., Bryan, J., Chang, W., D'Agostino McGowan, L., Francois, R., .....Yutani, H. (2019). Welcome to the Tidyverse. Journal of Open Souce Software, 4(43), 1-6. doi:https://doi.org/10.21105/joss.01686

Zepke, N., \& Leach, L. (2010). Improving student engagement: ten proposals for action. Active learning in higher education, II(S), 167-177.

Zepke, N., Leach, L., \& Butler, P. (2010). Student engagement: what is it and what influences it? Wellington: Teaching and learning research iniciative. 
ANEXOS 
Anexo 1: Matriz de consistencia

\begin{tabular}{|c|c|c|c|c|c|c|}
\hline Problemas & Objetivos & Hipótesis & Variables & Dimensiones & Metodología & $\begin{array}{c}\text { Población y } \\
\text { muestra }\end{array}$ \\
\hline General & General & General & 을 & $\begin{array}{l}\text { Establecimient } \\
\text { o de objetivos } \\
\text { y prioridades }\end{array}$ & $\begin{array}{c}\text { Tipo de } \\
\text { investigación: } \\
\text { Descriptivo y }\end{array}$ & $\begin{array}{c}\text { Población: } 450 \\
\text { estudiantes de } \\
\text { psicología de la } \\
\text { universidad } \\
\text { privada norbert } \\
\text { wiener. }\end{array}$ \\
\hline $\begin{array}{l}\text { ¿Cuál es la } \\
\text { relación entre } \\
\text { gestión del tiempd } \\
\text { y compromisd } \\
\text { académico er } \\
\text { estudiantes de } \\
\text { psicología } \\
\text { universidad } \\
\text { privada norbert } \\
\text { wiener, 2019? }\end{array}$ & 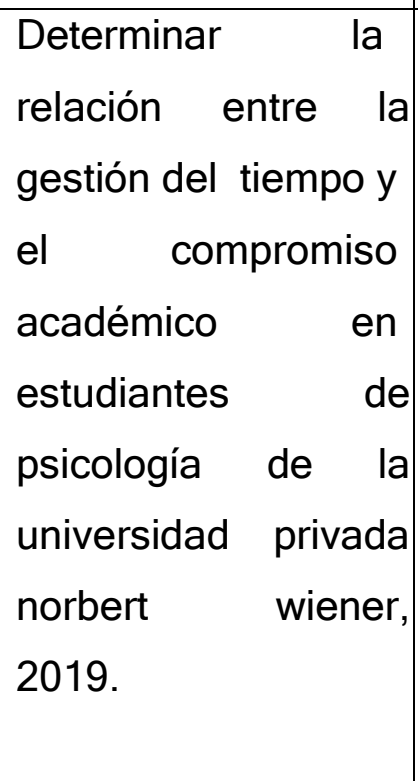 & $\begin{array}{l}\text { La gestión del tiempo y } \\
\text { el compromiso } \\
\text { académico están } \\
\text { relacionados de manera } \\
\text { directa } \\
\text { estadísticamente } \\
\text { significativa } \\
\text { estudiantes } \\
\text { psicología de de } \\
\text { universidad privada } \\
\text { norbert wiener, 2019. }\end{array}$ & 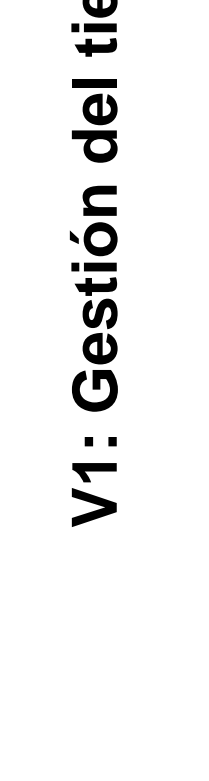 & $\begin{array}{c}\text { Herramientas } \\
\text { para la gestión } \\
\text { del tiempo }\end{array}$ & $\begin{array}{c}\text { Enfoque de } \\
\text { investigación: } \\
\text { Cuantitativo }\end{array}$ & $\begin{array}{l}\text { Muestra: } 209 \\
\text { estudiantes de } \\
\text { psicología de la } \\
\text { universidad } \\
\text { privada norbert } \\
\text { wiener. }\end{array}$ \\
\hline
\end{tabular}




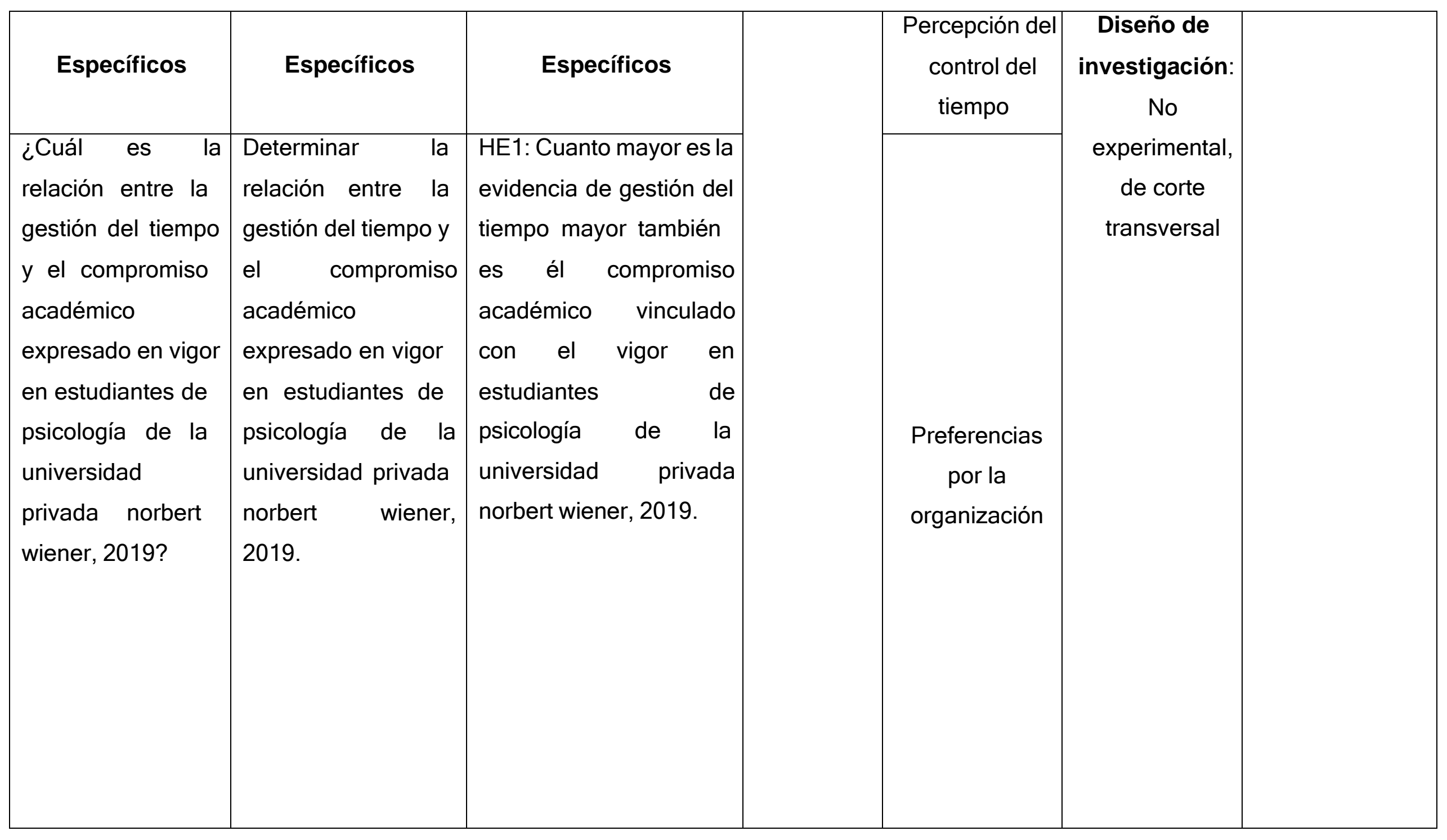




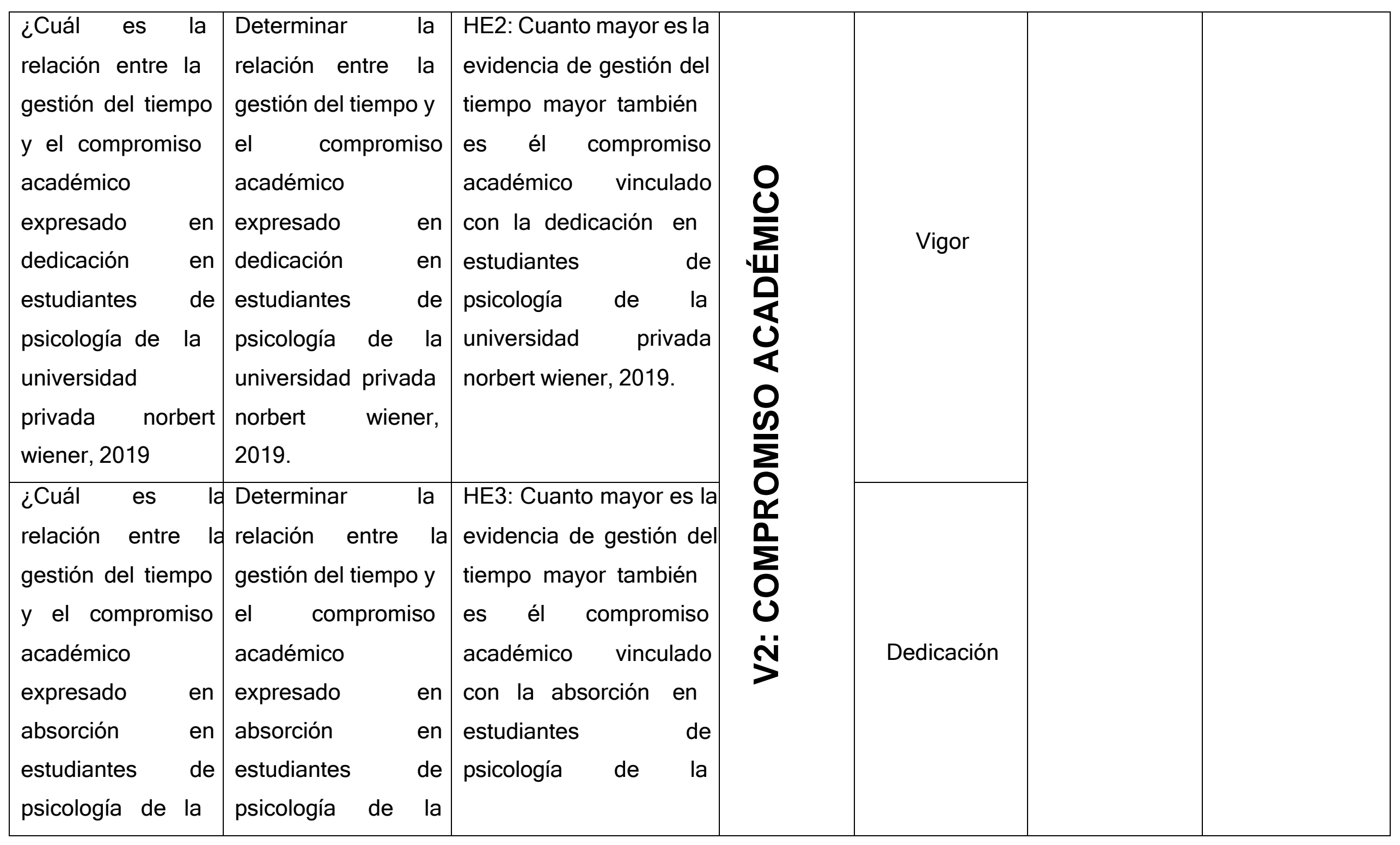




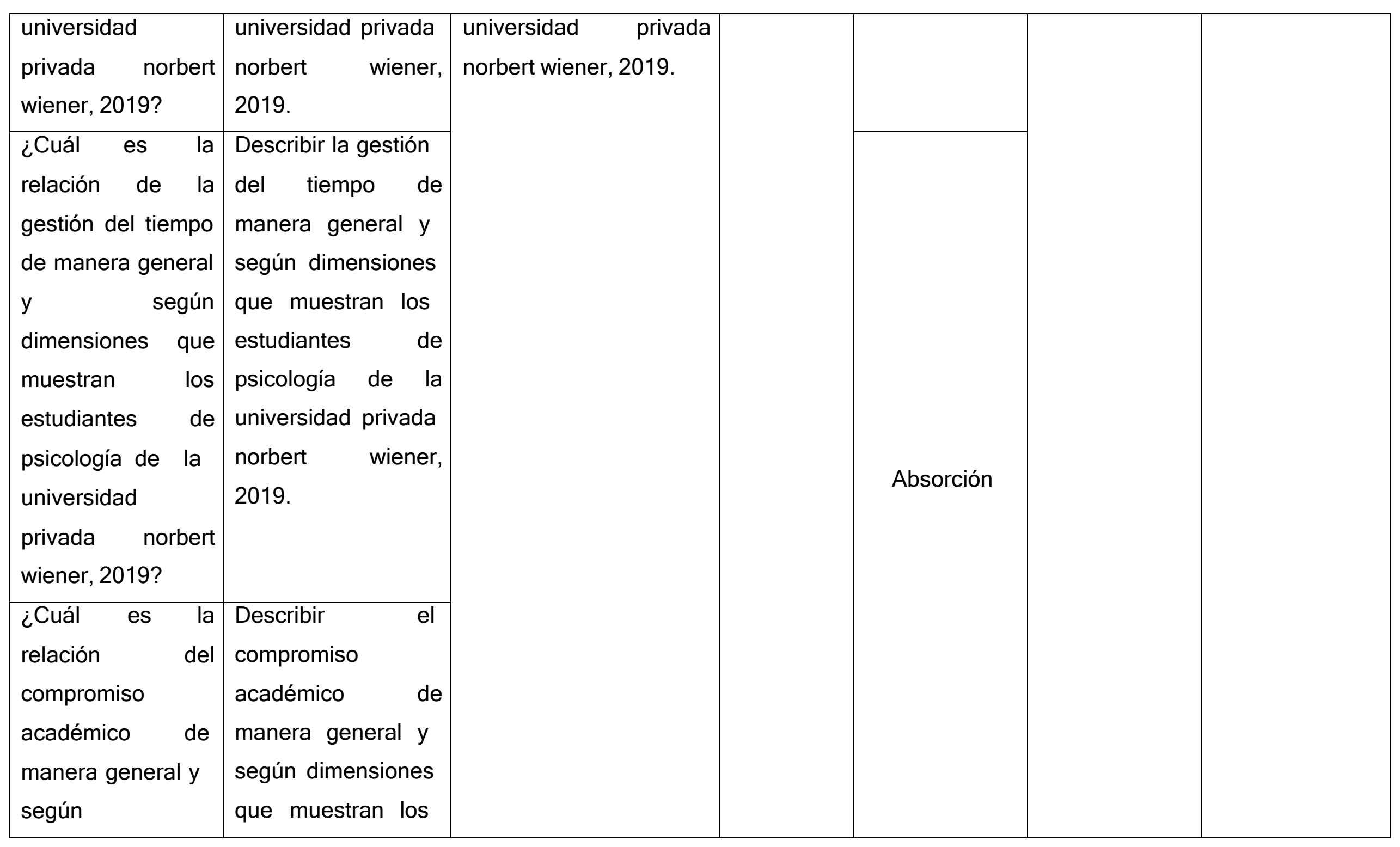




\begin{tabular}{|l|l|l|l|l|l|}
\hline dimensiones que & estudiantes de & & & \\
muestran los & psicología de la & & & \\
estudiantes de & universidad privada & & & \\
psicología de la & norbert riener, & & & \\
universidad & 2019. & & & & \\
privada norbert & & & & & \\
wiener, 2019? & & & & \\
\hline
\end{tabular}


Anexo 2: Instrumentos

\section{Escala de Comportamiento de Gestión del Tiempo}

\section{García y Pérez (2012)}

Estimado alumno, agradecido por su participación, lea las siguientes indicaciones.

De acuerdo a las alternativas planteadas. Por favor, marque la respuesta que represente su forma habitual de enfrentar los contextos estudiantiles.
(1) nunca
(2) pocas veces
(3) algunas veces
(4) habitualmente
(5) siempre

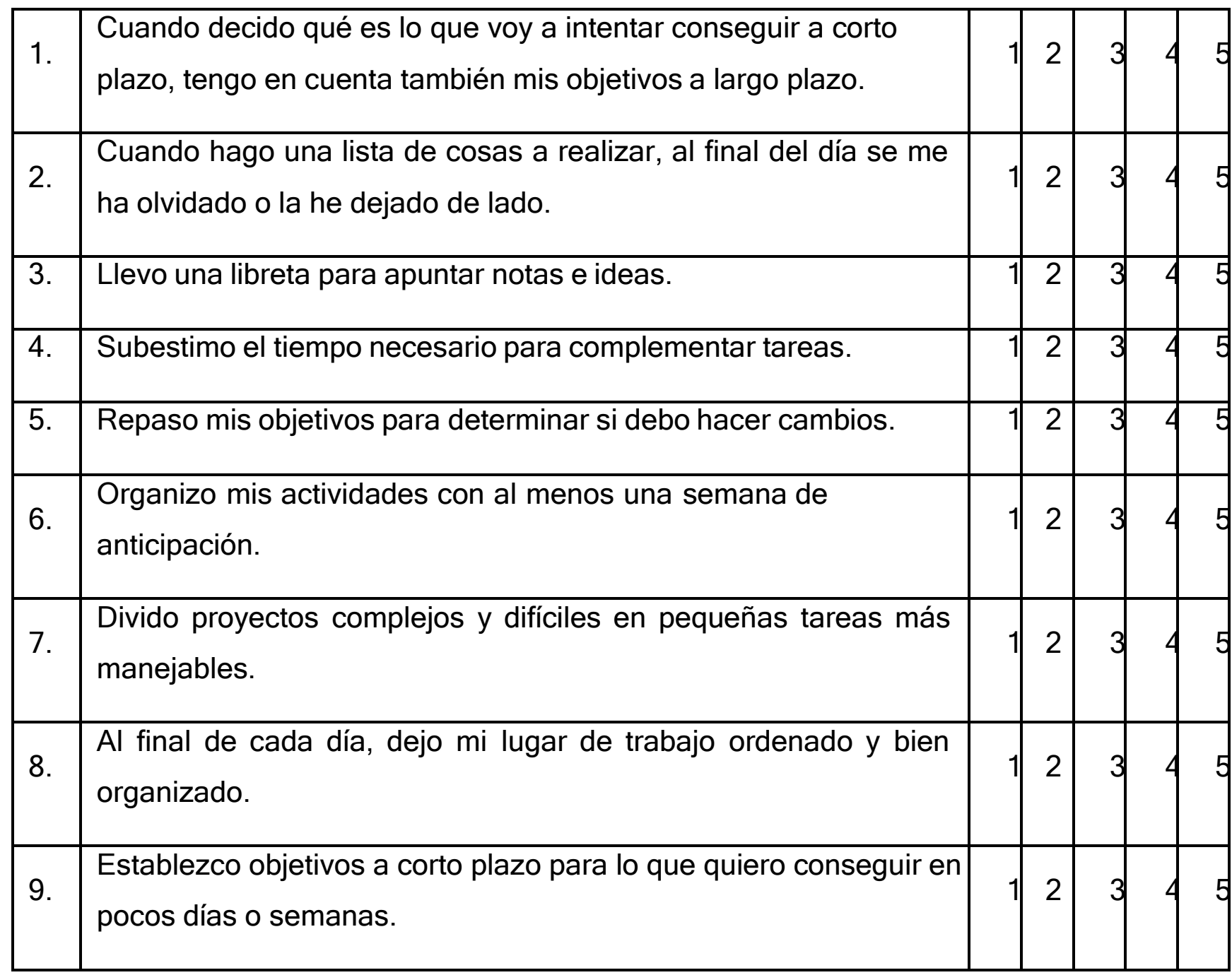




\begin{tabular}{|c|c|c|c|c|c|c|}
\hline 10 & Tengo la sensación de controlar mi tiempo. & 1 & 2 & 3 & 4 & 5 \\
\hline 11 & $\begin{array}{l}\text { Cuando observo que contacto frecuentemente con alguien, apunto } \\
\text { su nombre, dirección y número de teléfono en un lugar especial. }\end{array}$ & 1 & 2 & 3 & 4 & 5 \\
\hline 12 & $\begin{array}{l}\text { Puedo encontrar las cosas que necesito más fácilmente cuando mi } \\
\text { lugar de trabajo está "patas arriba” y desordenado que cuando está } \\
\text { ordenado y organizado. }\end{array}$ & 1 & 2 & 3 & 4 & 5 \\
\hline 13 & Marco fechas límite cuando me propongo realizar una tarea. & 1 & 2 & 3 & 4 & 5 \\
\hline 14 & Escribo notas para recordar lo que necesito hacer. & 1 & 2 & 3 & 4 & 5 \\
\hline 15 & Tengo que emplear mucho tiempo en tareas sin importancia. & 1 & 2 & 3 & 4 & 5 \\
\hline 16 & $\begin{array}{l}\text { El tiempo que empleo en gestionar el tiempo y organizar mi jornada } \\
\text { de trabajo es tiempo perdido. }\end{array}$ & 1 & 2 & 3 & 4 & \\
\hline 17 & $\begin{array}{l}\text { Busco maneras de incrementar la eficacia con que realizo las } \\
\text { actividades en mi trabajo. }\end{array}$ & 1 & 2 & 3 & 4 & 5 \\
\hline 18 & $\begin{array}{l}\text { Hago una lista de cosas que hacer cada día y pongo una señal al } \\
\text { lado cuando la he cumplido. }\end{array}$ & 1 & 2 & 3 & 4 & \\
\hline 19 & $\begin{array}{l}\text { Encuentro difícil mantener un horario porque los demás me } \\
\text { apartan de mi trabajo. }\end{array}$ & 1 & 2 & 3 & 4 & 5 \\
\hline 20 & $\begin{array}{l}\text { Mis jornadas de trabajo son demasiado impredecibles para } \\
\text { planificar y gestionar mi tiempo. }\end{array}$ & 1 & 2 & 3 & 4 & \\
\hline 21 & $\begin{array}{l}\text { Termino tareas de alta prioridad antes de realizar las menos } \\
\text { importantes. }\end{array}$ & 1 & 2 & 3 & 4 & \\
\hline 22 & Llevo una agenda conmigo. & 1 & 2 & 3 & 4 & 5 \\
\hline 23 & $\begin{array}{l}\text { Cuando estoy desorganizado soy más capaz de adaptarme a } \\
\text { acontecimientos inesperados. }\end{array}$ & 1 & 2 & 3 & 4 & 5 \\
\hline 24 & Repaso mis actividades diarias para ver donde pierdo el tiempo. & 1 & 2 & 3 & 4 & 5 \\
\hline 25 & Mantengo un diario de las actividades realizadas. & 1 & 2 & 3 & 4 & 5 \\
\hline
\end{tabular}




\begin{tabular}{|c|c|c|c|c|c|c|}
\hline 26 & $\begin{array}{l}\text { Tengo algunas de mis ideas más creativas cuando estoy } \\
\text { desorganizado. }\end{array}$ & 1 & 2 & 3 & & \\
\hline 27 & $\begin{array}{l}\text { Durante un día de trabajo evalúo si estoy cumpliendo con el horario } \\
\text { que he pre-establecido }\end{array}$ & 1 & 2 & 3 & 4 & \\
\hline 28 & Utilizo un sistema de bandejas para organizar la información. & 1 & 2 & 3 & 4 & 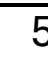 \\
\hline 29 & $\begin{array}{l}\text { Me doy cuenta de que estoy aplazando las tareas que no me } \\
\text { gustan pero que son necesarias }\end{array}$ & 1 & 2 & 3 & 4 & 5 \\
\hline 30 & $\begin{array}{l}\text { Noto que puedo hacer un mejor trabajo si aplazo las tareas que no } \\
\text { me gustan en lugar de intentar de hacerlas por orden de } \\
\text { importancia. }\end{array}$ & 1 & 2 & 3 & 4 & 5 \\
\hline 31 & $\begin{array}{l}\text { Establezco prioridades para determinar en qué orden haré las } \\
\text { tareas cada día. }\end{array}$ & 1 & 2 & 3 & 2 & 5 \\
\hline 32 & $\begin{array}{l}\text { Si sé que voy a tener que esperar un tiempo, preparo alguna tarea } \\
\text { para realizar mientras tanto. }\end{array}$ & 1 & 2 & 3 & & \\
\hline 33 & $\begin{array}{l}\text { Establezco bloques de tiempo en mis horarios para actividades } \\
\text { que hago habitualmente (compras, ocio, navegar por la web). }\end{array}$ & 1 & 2 & 3 & & \\
\hline 34 & $\begin{array}{l}\text { Encuentro lugares para trabajar donde puedo evitar interrupciones } \\
\text { y distracciones. }\end{array}$ & 1 & 2 & 3 & & \\
\hline
\end{tabular}


Versión en español para estudiantes

Escala de compromiso académico (UWES-S)

\begin{tabular}{|c|c|c|c|c|c|c|c|c|}
\hline & & 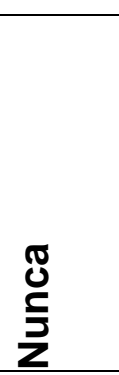 & 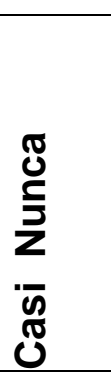 & 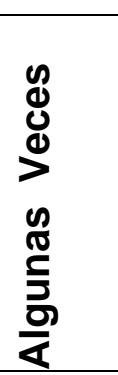 & 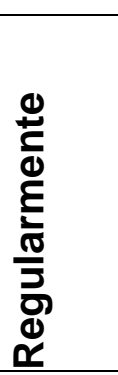 & 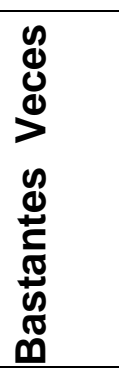 & 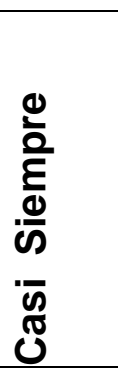 & 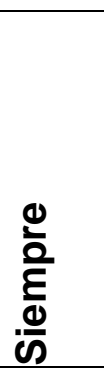 \\
\hline 1 & $\begin{array}{l}\text { Mis tareas como estudiante } \\
\text { me hacen sentir lleno de } \\
\text { energía }\end{array}$ & 0 & 1 & 2 & 3 & 4 & 5 & 6 \\
\hline 2 & $\begin{array}{l}\text { Creo que mi carrera tiene } \\
\text { significado }\end{array}$ & 0 & 1 & 2 & 3 & 4 & 5 & 6 \\
\hline 3 & $\begin{array}{l}\text { El tiempo "pasa volando" } \\
\text { cuando realizo mis tareas } \\
\text { como estudiante }\end{array}$ & 0 & 1 & 2 & 3 & 4 & 5 & 6 \\
\hline 4 & $\begin{array}{l}\text { Me siento fuerte y vigoroso } \\
\text { cuando estoy estudiando o voy } \\
\text { a las clases }\end{array}$ & 0 & 1 & 2 & 3 & 4 & 5 & 6 \\
\hline 5 & $\begin{array}{l}\text { Estoy entusiasmado con mi } \\
\text { carrera }\end{array}$ & 0 & 1 & 2 & 3 & 4 & 5 & 6 \\
\hline 6 & $\begin{array}{l}\text { Olvido todo lo que pasa } \\
\text { alrededor de mí, cuando estoy } \\
\text { abstraído con mis estudios. }\end{array}$ & 0 & 1 & 2 & 3 & 4 & 5 & 6 \\
\hline 7 & $\begin{array}{l}\text { Mis estudios me inspiran } \\
\text { cosas nuevas }\end{array}$ & 0 & 1 & 2 & 3 & 4 & 5 & 6 \\
\hline 8 & $\begin{array}{l}\text { Cuando me levanto por la } \\
\text { mañana me apetece ir a clase } \\
\text { o estudiar }\end{array}$ & 0 & 1 & 2 & 3 & 4 & 5 & 6 \\
\hline
\end{tabular}




\begin{tabular}{|c|c|c|c|c|c|c|c|c|}
\hline 9 & $\begin{array}{l}\text { Soy feliz cuando estoy } \\
\text { haciendo tareas relacionadas } \\
\text { con mis estudios }\end{array}$ & 0 & 1 & 2 & 3 & 4 & 5 & 6 \\
\hline 10 & $\begin{array}{l}\text { Estoy orgulloso de hacer esta } \\
\text { carrera }\end{array}$ & 0 & 1 & 2 & 3 & 4 & 5 & 6 \\
\hline 11 & Estoy inmerso en mis estudios & 0 & 1 & 2 & 3 & 4 & 5 & 6 \\
\hline 12 & $\begin{array}{l}\text { Puedo seguir estudiando } \\
\text { durante largos periodos de } \\
\text { tiempo }\end{array}$ & 0 & 1 & 2 & 3 & 4 & 5 & 6 \\
\hline 13 & Mi carrera es retadora para mí & 0 & 1 & 2 & 3 & 4 & 5 & 6 \\
\hline 14 & $\begin{array}{l}\text { Me "dejo llevar" cuando realizo } \\
\text { mis tareas como estudiante }\end{array}$ & 0 & 1 & 2 & 3 & 4 & 5 & 6 \\
\hline 15 & $\begin{array}{l}\text { Soy muy "resistente" } \\
\text { afrontar mis tareas } \\
\text { estudiante }\end{array}$ & 0 & 1 & 2 & 3 & 4 & 5 & 6 \\
\hline 16 & $\begin{array}{l}\text { Es difícil para mí separarme de } \\
\text { mis estudios }\end{array}$ & 0 & 1 & 2 & 3 & 4 & 5 & 6 \\
\hline 17 & $\begin{array}{l}\text { En mis tareas como estudiante } \\
\text { no paro incluso si no me } \\
\text { encuentro bien }\end{array}$ & 0 & 1 & 2 & 3 & 4 & 5 & 6 \\
\hline
\end{tabular}


Anexo 3: Validez y fiabilidad de los instrumentos

Validez y fiabilidad de la Escala de Comportamiento de Gestión del Tiempo

\begin{tabular}{cccccccc}
\hline $\begin{array}{c}\text { Establecimiento } \\
\text { de objetivos y } \\
\text { prioridades }\end{array}$ & $\begin{array}{c}\text { Herramientas para } \\
\text { la gestión del } \\
\text { tiempo }\end{array}$ & $\begin{array}{c}\text { Percepción del } \\
\text { control del tiempo }\end{array}$ & $\begin{array}{c}\text { Preferencias por la } \\
\text { desorganización }\end{array}$ \\
\hline Ítems & $\lambda$ & Ítems & $\lambda$ & Ítems & $\lambda$ & Ítems & $\lambda$ \\
& & & & & & & \\
T1 & .544 & $\mathrm{~T} 3$ & .475 & $\mathrm{~T} 4$ & .494 & $\mathrm{~T} 2$ & .467 \\
T5 & .401 & $\mathrm{~T} 6$ & .456 & $\mathrm{~T} 10$ & .664 & $\mathrm{~T} 8$ & .313 \\
T7 & .432 & $\mathrm{~T} 11$ & .723 & $\mathrm{~T} 15$ & .758 & $\mathrm{~T} 12$ & .578 \\
T9 & .444 & $\mathrm{~T} 14$ & .368 & $\mathrm{~T} 19$ & .393 & $\mathrm{~T} 16$ & .536 \\
T13 & .521 & $\mathrm{~T} 18$ & .522 & $\mathrm{~T} 29$ & .480 & $\mathrm{~T} 20$ & .689 \\
T17 & .307 & $\mathrm{~T} 22$ & .523 & & & $\mathrm{~T} 23$ & .720 \\
T21 & .311 & $\mathrm{~T} 25$ & .601 & & & $\mathrm{~T} 26$ & .434 \\
T24 & .549 & $\mathrm{~T} 28$ & .580 & & & $\mathrm{~T} 30$ & .318 \\
T27 & .470 & $\mathrm{~T} 32$ & .527 & & & & \\
T31 & .456 & $\mathrm{~T} 33$ & .516 & & & & \\
& & $\mathrm{~T} 34$ & .360 & & & &
\end{tabular}

Coeficiente omega Coeficiente omega Coeficiente omega Coeficiente omega
$\omega=.773$
$\omega=.827$
$\omega=.654$
$\omega=.676$

Análisis factorial confirmatorio (AFC). Se utilizó el estimador máximo verosimilitud robusta (MLR) debido a que el coeficiente de Mardia fue $<.70$, siendo un valor de 12.46. En ese sentido, los índices de ajuste fueron satisfactorios $\mathrm{CFI}=.95, \mathrm{TLI}=$ .95, RMSEA = .05 [IC 90\%; 0.041-0.067]. La consistencia interna se evaluó con el coeficiente omega, cuyos valores fueron aceptables para cada factor: Establecimiento $\omega=.773$, Herramientas $\omega=.827$, Percepción $\omega=.654 \mathrm{y}$ Preferencias $\omega=.676$. 
Validez y fiabilidad de la Escala de Compromiso Académico (UWES-S)

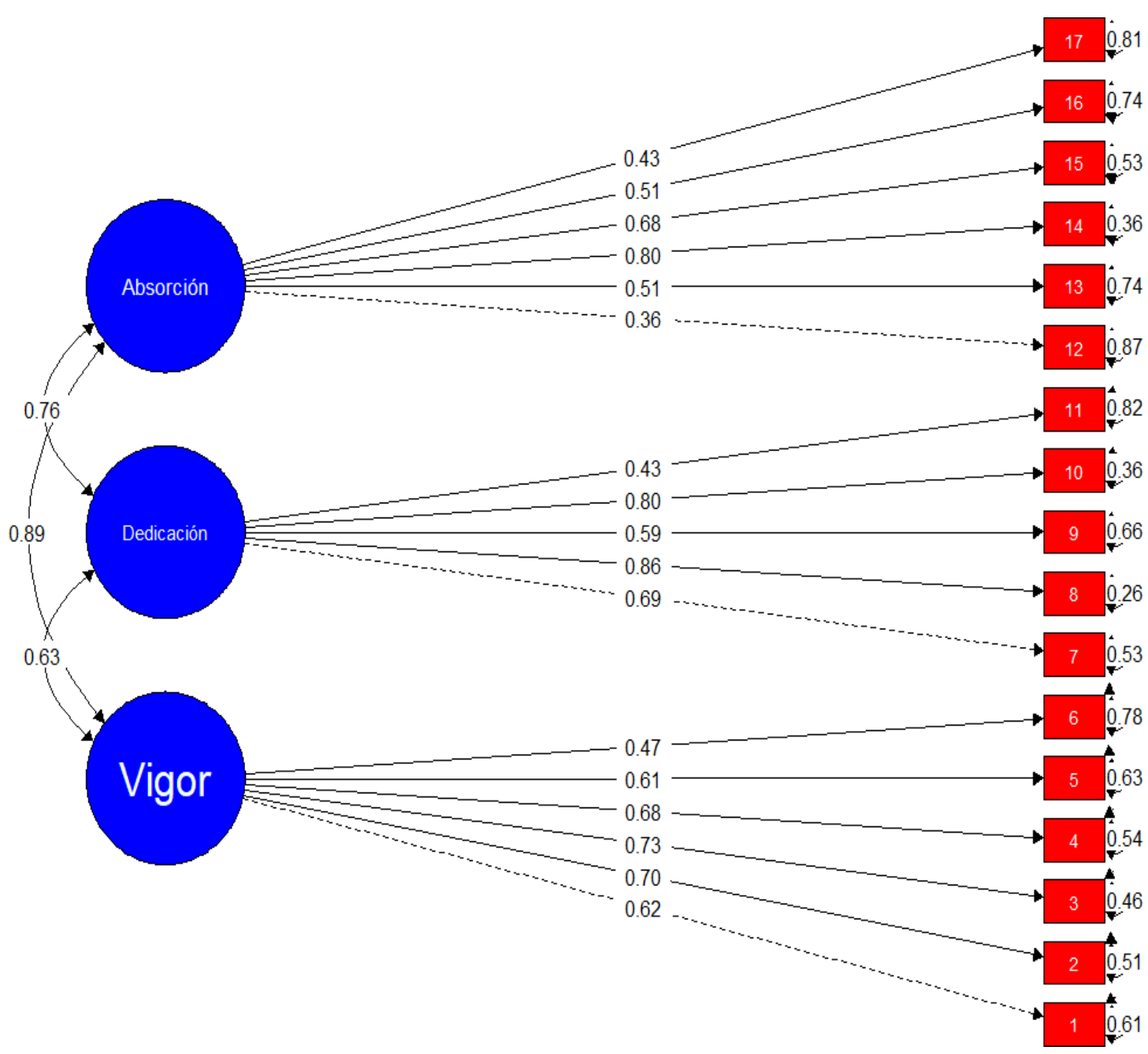

Análisis factorial confirmatorio (AFC). Se utilizó el estimador máximo verosimilitud robusta $(M L R)$ debido a que el coeficiente de Mardia fue $<.70$, siendo un valor de 25.79. En ese sentido, los índices de ajuste fueron satisfactorios $\mathrm{CFI}=.92, \mathrm{TLI}=$ .90, RMSEA = .06 [IC 90\%; 0.052-0.079]. La consistencia interna se evaluó con el coeficiente omega, cuyos valores fueron aceptables para cada factor: vigor $\omega=$ .812 , dedicación $\omega=.816$, absorción $\omega=.755$. 
Anexo 4: Permiso institucional

Cercado de Lima, 19 de setiembre de 2019

\author{
Universidad Privada Norbert Wiener \\ Director Académico de la EAP de Psicologia \\ Av. Arequipa 440 con Jr. Larrabure y Unanue 110
}

Yo, Victor Manuel Urbano Katayama, identificado con DNI $\mathrm{N}^{\circ} 06646690$, en mi calidad de Director Académico (encargado) de la Escuela Académica Profesional de Psicologia de la Universidad Privada Norbert Wiener, autorizo a Jonatan Humberto Baños Chaparro, bachiller en psicologia por la Universidad Privada Norbert Wiener y estudiante de la maestria en educación con mención en docencia e investigación universitaria de la Universidad de San Martin de Porres, a aplicar los instrumentos de recolección de datos relacionada a su tesis de maestria.

El interesado asume que toda información y el resultado de la investigación serán de uso exclusivamente académico.

La información servirá como base para la construcción de una base de datos. cuyos resultados obtenidos podrian llegar a convertirse en una herramienta didactica que apoye la formación de los estudiantes de la Escuela Académica Profesional de Psicologia.

Atentamente

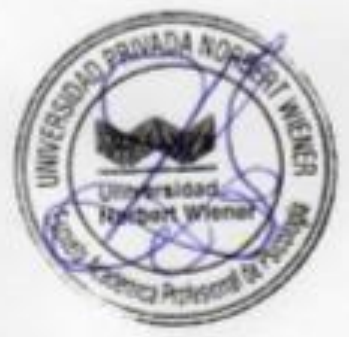

